\title{
EL PAPEL DE LAS CHOPERAS DE REPOBLACIÓN EN LA DINÁMICA DEL PAISAJE DEL RÍO PISUERGA EN SUS TRAMOS MEDIO Y BAJO (S.XX-XXI)
}

\author{
Alicia Vadillo González \\ Departamento de Geografía. Universidad Autónoma de Madrid \\ alicia.vadillo@uam.es
}

\section{RESUMEN}

Las repoblaciones forestales con frondosas de crecimiento rápido han sido, y continúan siendo hoy, elemento y factor claves en la configuración del mosaico paisajístico de los valles interiores de la cuenca del Duero. En los tramos medio y bajo del río Pisuerga, la ubicación de las "choperas" en los sectores próximos a las márgenes fluviales - como principal alternativa productiva a la actividad agropecuaria adquirió especial relevancia durante la segunda mitad del siglo XX, prolongándose también en los inicios del siglo XXI. El resultado es la consolidación de un continuo forestal con implicaciones socioeconómicas, ecológicas y paisajísticas distintas en el paisaje ribereño heredado de finales del siglo XIX. Con objeto de conocer el signo y la intensidad de estas dinámicas, sus efectos y los agentes implicados, se presenta un análisis de la evolución del elemento forestal y de su relación con el espacio fluvial y ribereño, desde una aproximación compleja, multidimensional y transdisciplinar. La búsqueda de información documental y bibliográfica, la elaboración de un SIG específico para el ámbito de estudio y la aplicación e interpretación de los datos obtenidos de los "Índices del paisaje", son los principales recursos de la propuesta metodológica definida para esta investigación ${ }^{1}$.

Palabras clave: choperas de repoblación, paisaje ribereño, dinámicas paisajísticas, transdisciplinariedad, "Índices del paisaje" y SIG.

\section{ABSTRACT \\ The role of poplar afforestation in the landscape dynamics of the middle and low course of Pisuerga River (20th and 21th centuries)}

The poplar afforestation projects have been, and remain today, one of the most important elements in the landscape evolution of the Duero River Basin. In the middle and low courses of Pisuerga River, the location of these "poplar projects" next to the river banks took special relevance, as the main productive alternative to farming, during the second half of the twentieth century, also extending in early twenty-first century. The result has been the consolidation of a "forest continuum" with different socio-economic, ecological and landscape consequences for the riparian landscape of Pisuerga River, which was inherited from the late nineteenth century. In order to know the tendency and intensity of these dynamics, their effects and the role of the different agents that were involved, we analyse the evolution of the "poplars" in the landscape of the valley, and its relation to the river and the riparian areas, from a complex, multidimensional and transdisciplinary approach. The search for documental and bibliographic information, the creation of a specific GIS for the Pisuerga River and the application of the "Landscape Metrics", are the main resources of the methodology defined for this research.

\footnotetext{
1 Este trabajo forma parte de los resultados obtenidos del proyecto de investigación de tesis doctoral, Los paisajes del Duero: el río Pisuerga, naturaleza y cultura en torno al agua, realizado y defendido por la autora en el Departamento de Geografía de la Universidad Autónoma de Madrid (2009-2014)
} 
Key words: poplar afforestation, riparian landscape, landscape dynamics, transdisciplinary method, "Landscape Metrics" and GIS.

\section{INTRODUCCIÓN}

El progreso socioeconómico y tecnológico experimentado por la sociedad ha alterado profundamente la percepción humana del medio natural y sus recursos en las dos últimas centurias (Décamps et al., 1988; Sanz, 1996). Estas alteraciones, ligadas al control progresivo del hombre sobre la naturaleza, han provocado la ruptura de las relaciones tradicionales entre los sistemas de producción y el medio físico, generando profundos cambios en la organización de la ocupación del suelo (Burel y Baudry, 2002).

La potenciación de la variable antrópica por los nuevos modelos de desarrollo territorial se ha traducido, por un lado, en la reducción del papel de las variables ambientales en el proceso de construcción paisajística, y por otro, en la intensificación y la expansión de las estructuras humanas modernas, un proceso que no sólo ha perturbado profundamente el sistema natural, sino también las estructuras humanas de carácter tradicional (Gómez, 1997; Jongman, 2002; Vélez y Gómez, 2008). Ambas dinámicas han supuesto importantes implicaciones ecológicas y paisajísticas en materia de heterogeneidad y complejidad estructural, así como en la conectividad y la potencialidad ecológica de los elementos que componen el paisaje.

El aprovechamiento secular del río y las riberas por la sociedad ha generado distintos cambios en la composición y la configuración espacial de los mosaicos paisajísticos vinculados a los cursos fluviales. La acción humana cobra especial protagonismo como elemento y motor fundamental del proceso de construcción y ajuste espacial reciente de estos paisajes (Forman y Gordon, 1981; Malanson, 1993; Vila et al., 1996; Sanz, 1996). El tipo y la intensidad de las alteraciones producidas han estado determinados por los contextos territoriales dominantes, afectando tanto a la estabilidad individual de los elementos, como a la estructura del conjunto paisajístico (Xiao et al, 1990; Li, 1997).

Los espacios ribereños, definidos como importantes corredores de energía, materia y organismos, y como sectores de ecotono entre el medio fluvial y el terrestre, han sido fuertemente fragmentados e intensamente reducidos en los dos últimos siglos (Forman y Gordon, 1981; Naiman et al., 1988). Las principales alteraciones ocurridas están relacionadas fundamentalmente con la regulación total del hidrosistema, la ocupación progresiva de las márgenes fluviales (equipamientos, repoblaciones forestales, usos agropecuarios, proyectos de urbanización, etc.) y la consiguiente desaparición del bosque de ribera (Pautou y Décamps, 1985; Sanz, 1996).

Los efectos ecológicos y paisajísticos de estos procesos son diversos. Destacan, entre otros, la reducción de las tasas de diversidad ecológica y paisajística (Gurrutxaga y Lozano, 2006; Molina, Sanz y Mata, 2010) y la pérdida de sus funciones esenciales como corredores y hábitats de especiales condiciones ambientales (Forman y Gordon, 1986; Malanson, 1993; Wiens, 2002), como filtro y sumidero de sustancias y especies (Sterling, 1996), y como elementos de referencia en el conjunto paisajístico (Malanson, 1993; Ollero, 2001; Décamps, 2001; Ribas, 2006; Frolova, 2007; Panareda, 2009; Mata, Molina y Sanz, 2010; Mata y Fernández, 2010).

\section{1. Área de estudio}

En los valles interiores de la cuenca del Duero, y en el valle del río Pisuerga en particular, el cambio de modelo socioeconómico y las profundas transformaciones experimentadas por el sistema territorial durante la pasada centuria y principios de la actual han provocado importantes perturbaciones en los paisajes heredados de finales del siglo XIX. Estos cambios han sido especialmente acusados en los terrenos más próximos a los cursos fluviales y en las zonas afectadas por especiales condiciones ambientales.

Previamente, estos biotopos con nula o escasa productividad agrológica - debido al encharcamiento persistente y la presencia de suelos poco desarrollados - permanecían aparentemente inalterados en las riberas del Pisuerga. Eran sectores de formación aluvial correspondientes a hábitats naturales que conservaban más o menos sus caracteres primigenios, los cuales estaban ocupados por formaciones riparias con cierto grado de naturalidad y diversidad ecológica, como los sotos residuales - generalmente desestructurados - y las praderas juncales. 
Mapa 1. Localización del ámbito de estudio

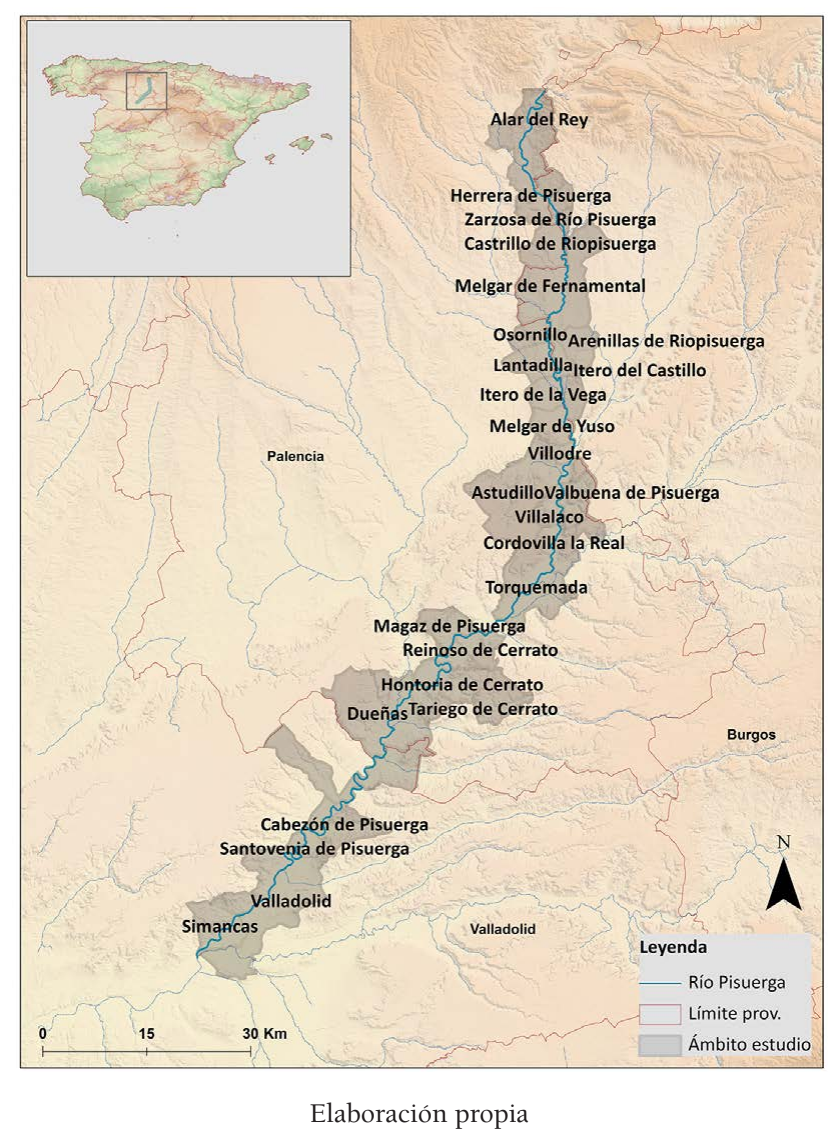

A principios del siglo XX, el interés creciente por gestionar desde un punto de vista productivo estos espacios - tal y como ya sucedía en las márgenes de su tributario, el río Carrión ${ }^{2}$ - y la necesidad de paliar los efectos del elevado grado de deterioro de sus márgenes (figura 2), hicieron proliferar un mosaico nuevo de usos y aprovechamientos en el paisaje de ribera del Pisuerga. Entre los núcleos de Alar del Rey (Palencia) y de Simancas (Valladolid), el inicio de grandes proyectos de repoblación forestal con especies de crecimiento rápido en las márgenes del río supuso un cambio importante en el tipo y la intensidad de explotación de estos sectores, modificando sustancialmente sus estructuras, sus funciones y sus dinámicas originales (mapa 1). Hasta ese momento, la presencia del hombre en las riberas del Pisuerga a lo largo del cauce se había limitado al pastoreo, la saca de leña muerta y el emplazamiento de infraestructuras hidráulicas tradicionales, como molinos, batanes o pequeñas centrales eléctricas. Los nuevos aprovechamientos forestales son resultado de la política hidro-forestal puesta en marcha por la Confederación Hidrográfica del Duero durante el primer tercio del siglo XX, e intensificada posteriormente en la segunda mitad del mismo. El proceso de ocupación paulatina de los espacios de mayor inestabilidad del cauce y de la llanura de inundación por estas manchas de frondosas - popularmente conocidas como "choperas" o "plantíos" - jugó y, continúan jugando hoy, un papel fundamental en la dinámica espacial del mosaico paisajístico ribereño vinculado a este río.

\section{OBJETIVOS Y MÉTODOS DE TRABAJO}

Los objetivos de este estudio se centran en el análisis y la caracterización del proceso de reconfiguración y reestructuración paisajística sucedido en las riberas del río Pisuerga a lo largo del siglo XX y prin-

2 Así lo recogen los Preliminares correspondientes al Proyecto de Repoblación y Fijación del Río Pisuerga en el Término Municipal de Melgar de Fernamental - Provincia de Burgos (1929): «Iniciados los trabajos de repoblación y fijación de los ríos de la cuenca del Duero, con los correspondientes a las del río Carrión y término municipal (...), se pensó en la conveniencia de extenderlos en la medida que lo permitiera los recursos disponibles, tanto económicos como técnicos. (...) Uno de los cuales es el presente, que se refiere a un solo término municipal de los atravesados por el río Pisuerga $(. .$.$) »$ 
cipios del XXI. En concreto, se ajustan al papel protagonista de los proyectos de repoblación forestal en el desarrollo del paisaje ribereño actual, y en la identificación, caracterización y valoración de las distintas implicaciones ecológicas y paisajísticas que su presencia ha generado en el mosaico paisajístico heredado de finales del siglo XIX.

Los métodos dispuestos para sendos propósitos se asientan sobre el concepto más reciente de paisajes riparios, entendidos como sistemas complejos, únicos y dinámicos (Malanson, 1993; Sterling, 1996; Sanz, 1996; Sanz, Molina y Mata, 2010). La complejidad y la diversidad del concepto han exigido la aplicación de una metodología múltiple, abierta e interdisciplinar. En este marco de trabajo, se han tratado de integrar las tareas de búsqueda bibliográfica y documentación histórica sobre el proceso de reforestación de las márgenes fluviales y el contexto territorial dominante, con las técnicas de inventariado florístico y estructural de las masas de vegetación riparia sobrevivientes, y el análisis cuantitativo de las principales dinámicas espaciales que han dirigido el proceso de redefinición paisajística. En el desarrollo de estas tareas, la relación de los métodos tradicionales del estudio "histórico-geográfico" con otros más recientes, como son los Sistemas de Información Geográfica (SIG) y los "Índices del paisaje" en la Ecología del Paisaje (Landscape metrics), han proporcionado información relevante y contrastada sobre la evolución del paisaje de estos sectores y el protagonismo adquirido por las choperas de repoblación en el mismo.

Tabla 1. Taxonomía paisajística de las riberas del río Pisuerga.

\begin{tabular}{|c|c|c|c|}
\hline Mosaico & $\begin{array}{l}\text { Categorías - } \\
\text { Conjuntos }\end{array}$ & Tipos & Definición \\
\hline \multirow{6}{*}{$\begin{array}{l}\text { Riberas del } \\
\text { Pisuerga } \\
\text { (curso medio } \\
\text { y bajo) }\end{array}$} & \multirow{3}{*}{$\begin{array}{l}\text { Espacios de } \\
\text { vegetación } \\
\text { natural y } \\
\text { seminatural de } \\
\text { ribera }\end{array}$} & Sotos & $\begin{array}{l}\text { Cobertura natural simple. Masas de vegetación pluriestratas, uniformes, continúas } \\
\text { en su desarrollo y con una anchura mínima de } 10 \text { metros. Las principales especies } \\
\text { son Populus nigra, Fraxinus angustifolia, Salix alba y Populus alba. En los estratos in- } \\
\text { feriores dominan Salix salviifolia, Salix alba, Crataegus monogyna, Rubus ulmifolius, } \\
\text { Rubus caesius, etc. }\end{array}$ \\
\hline & & $\begin{array}{l}\text { Praderas } \\
\text { juncales }\end{array}$ & $\begin{array}{l}\text { Cobertura natural simple que incluye comunidades características de ámbitos flu- } \\
\text { viales, definidas por la abundancia, la densidad y el predominio de elementos her- } \\
\text { báceos. Estas comunidades integran tanto herbazales estrictamente aluviales, como } \\
\text { comunidades primocolonizadoras características de estaciones secas o con acusada } \\
\text { sequedad estacional. }\end{array}$ \\
\hline & & Doseles & $\begin{array}{l}\text { Cobertura natural simple. Comunidades forestales de ribera compuestas por un } \\
\text { estrato arbóreo, arbustivo o arborescente, incluyendo los estados jóvenes y regene- } \\
\text { rados de los mismos. Se corresponden con retazos de los bosques aluviales origi- } \\
\text { narios. Presentan estructuras estrechas desorganizadas, lineales y con una anchura } \\
\text { menor a } 10 \mathrm{~m} \text {. Las principales especies en el estrato arbóreo son el chopo negro } \\
\text { (Populus nigra), el fresno (Fraxinus angustifolia) y el sauce blanco (Salix alba). En el } \\
\text { estrato arborescente y arbustivo dominan los ejemplares de sauces (Salix alba, Salix } \\
\text { salviifolia, Salix triandra, Salix eleagnos, Salix purpurea) y en el estrato herbáceo se } \\
\text { identifica un mosaico heterogéneo de especies potenciales de los bosques de ribera } \\
\text { y/o colonizadoras procedentes de la vega. }\end{array}$ \\
\hline & $\begin{array}{c}\text { Espacio } \\
\text { humano/Vega }\end{array}$ & $\begin{array}{c}\text { Choperas/ } \\
\text { Plantaciones }\end{array}$ & $\begin{array}{l}\text { Cobertura simple. Plantaciones forestales de estrato arbóreo dominante que incluye } \\
\text { los estados jóvenes y regenerados de los mismos. Las principales especies utilizadas } \\
\text { son los híbridos o clones del género Populus (Populus } x \text { canadensis, } P \text {. x euroameri- } \\
\text { cana, P. x deltoides, P. x italica,...), acompañados por un estrato herbáceo escaso y } \\
\text { empobrecido (Elymus repens, Brachypodium phoenicoides, Dactylis glomerata). }\end{array}$ \\
\hline & & Vega agraria & $\begin{array}{l}\text { Cobertura compuesta de dominante agraria. Representa la mayor parte de la plana } \\
\text { aluvial transformada por el hombre mediante su puesta en cultivo (regadío, secano, } \\
\text { hortícola). Se extiende preferentemente por los sectores no-inundables de la llanura } \\
\text { de inundación y en las terrazas más bajas. }\end{array}$ \\
\hline & & Otros usos & $\begin{array}{l}\text { Cobertura artificial compuesta. Está integrada por el resto de usos del suelo que } \\
\text { componen el espacio humano. Destacan, por su extensión y su relevancia en el } \\
\text { paisaje, los asentamientos de población y los distintos equipamientos e infraes- } \\
\text { tructuras que lo articulan. }\end{array}$ \\
\hline
\end{tabular}

Elaboración propia.

La elaboración de un SIG específico para el ámbito de esta investigación ha facilitado notablemente las tareas de identificación, representación y cuantificación de la evolución y los efectos sobre el área forestal. Este análisis se ha desarrollado desde un enfoque multiescalar, en el que se han combinado la visión diacrónica del mosaico paisajístico - en las cesuras temporales de 1900, 1956 y 2006 - con la visión sincrónica del mismo entre el curso medio y bajo del río. Las imágenes seleccionadas se corresponden con el material cartográfico disponible para el periodo de estudio (s. XX-XXI): las series históricas del mapa topográfico del IGN (1:50.000), la fotografía del vuelo americano de 1956 y la ortofotografía del PNOA para 2006. 
Tras las pertinentes tareas de georreferenciación, fotointerpretación y digitalización, el mosaico de coberturas resultante para el sector ribereño se compone de distintas categorías y tipos de usos del suelo, cada una de los cuales responde a unos rasgos, funciones y dinámicas particulares recogidas en la tabla 1. Se han diferenciado dos categorías generales; por un lado, los "espacios de vegetación natural y seminatural de ribera", compuestos por las coberturas de "sotos", "sotos abiertos", "praderas juncales" y "doseles", y por otro, el espacio de "vega" o humanizado, con las "choperas/plantaciones", la "vega agraria" y "otros usos", como principales coberturas de detalle. Los criterios generales de clasificación se basan fundamentalmente en la dominancia del factor humano o del factor natural en la composición y configuración de cada una. Para los tipos de cobertura se consideran, además, otras variables relacionadas con la composición florística y la complejidad fisonómica, en el caso de las coberturas naturales, y con el tipo de actividad, su grado de artificialidad e impacto, en las coberturas de dominante humana.

Los resultados del análisis espacial, completado con el cálculo de los "Índices del paisaje" en materia de complejidad, conectividad y heterogeneidad paisajística mediante la extensión para ArcGis 10.1 denominada Patch / Grid Analyst (Spatial Statistics - FragStats Interface) (Elkie et al., 1999), se han combinado con la información cualitativa tomada directamente de los proyectos técnicos de repoblación forestal, elaborados por el Servicio Forestal de la Confederación Hidrográfica del Duero. El Archivo Histórico Provincial de Valladolid y el Archivo Histórico de la Confederación han sido los principales centros de información bibliográfica y documental consultados.

La integración de los "Índices del paisaje" en el estudio paisajístico ha permitido cuantificar la evolución del componente humano - representado en este estudio por los "plantíos" - respecto al elemento natural (sotos, sotos abiertos, etc.) en la composición y la configuración espacial del paisaje ribereño. Los parámetros aplicados se han adaptado a la información requerida en materia de representatividad paisajística (LAND), extensión (MPS), fragmentación (NP), simplificación (AWMPFD), potencialidad (MCA) y conectividad (MNN) de los distintos fragmentos que componen el mosaico paisajístico (tabla 2). El cálculo de estos estadísticos se ha desarrollado en los tres cortes temporales definidos en el SIG (1900/1956/2006), desde un nivel intermedio de análisis o class level, en el que se integra la taxonomía de coberturas de usos del suelo sintetizada en la tabla 1. La representación gráfica de las principales dinámicas espaciales identificadas y valoradas se ha elaborado mediante gráficas estadísticas y mapas de evolución de paisaje.

Tabla 2. "Índices del paisaje" incorporados en el análisis paisajístico.

\begin{tabular}{|l|c|c|c|}
\hline \multirow{4}{*}{ Índices del paisaje } & \multicolumn{2}{|c|}{ Tipo } & Definición \\
\cline { 3 - 4 } & \multirow{4}{*}{ Composición } & Área & LAND (Total Area Landscape) \\
\cline { 3 - 4 } & \multirow{2}{*}{ Superficie y variabilidad } & MPS (Mean Patch Size) \\
\cline { 3 - 4 } & & Forma & NP (Number of Patches) \\
\cline { 3 - 4 } & & Hábitat interior o core area & MCA (Mean Core Area) \\
\cline { 3 - 4 } & \multirow{3}{*}{ Configuración } & Distancia al vecino & MNN (Mean Nearest Neighbour) \\
\cline { 3 - 4 } & & y conectividad & MPI (Mean Proximity Index) \\
\cline { 3 - 4 } & Contagio e intercalado & IJI (Interspersion and Juxtaposition Index) \\
\cline { 3 - 4 } & &
\end{tabular}

Fuente: Elkie et al., 1999.

Por último, el método de muestreo de las formaciones de vegetación riparia del Pisuerga cierra el cuadro metodológico propuesto. El estudio biogeográfico se ha centrado en el inventario estructural y florístico de las principales manchas de vegetación natural y seminatural confinadas actualmente entre la orilla del río y el límite con el espacio de vega ${ }^{3}$, en el sector comprendido entre el núcleo de Alar del Rey y la desembocadura del Pisuerga en el río Duero. Las formaciones identificadas se aproximan a las coberturas de vegetación riparia definidas en el SIG del Pisuerga, optimizando el análisis realizado de los cambios de paisaje.

\section{ANÁLISIS Y RESULTADOS}

Se reconocen tres escenarios principales en la evolución del elemento forestal coincidentes con las cesuras temporales definidas en el SIG del Pisuerga (1900/1956/2006). El análisis de cada escenario re-

3 Sector relativo a la «unidad de ribera» (bankfull, llanura de inundación y zonas de retención de agua) (Vadillo, 2014: 31). 
vela implicaciones ecológicas y paisajísticas de diferente signo e intensidad, las cuales se sintetizan en las dinámicas generales de fragmentación, simplificación y desconexión de las formaciones de vegetación riparia residual - representadas mediante el conjunto de coberturas de "espacios naturales y seminaturales de vegetación de ribera" o conjunto ribereño -, frente a las dinámicas de extensión y compactación de los terrenos de repoblación forestal y del conjunto de "vega". En la figura 1 se aprecian ambas tendencias mediante la evolución experimentada por el índice LAND, o de representatividad paisajística, en cada una de las etapas delimitadas. La tendencia al alza de la variable humana domina la composición y la configuración actual de estos paisajes, intensificándose especialmente durante la segunda mitad del siglo XX.

Figura 1. Evolución general de los valores de representatividad paisajística (\%LAND) de los conjuntos de "ribera" y "vega", y de la cobertura de "plantaciones".

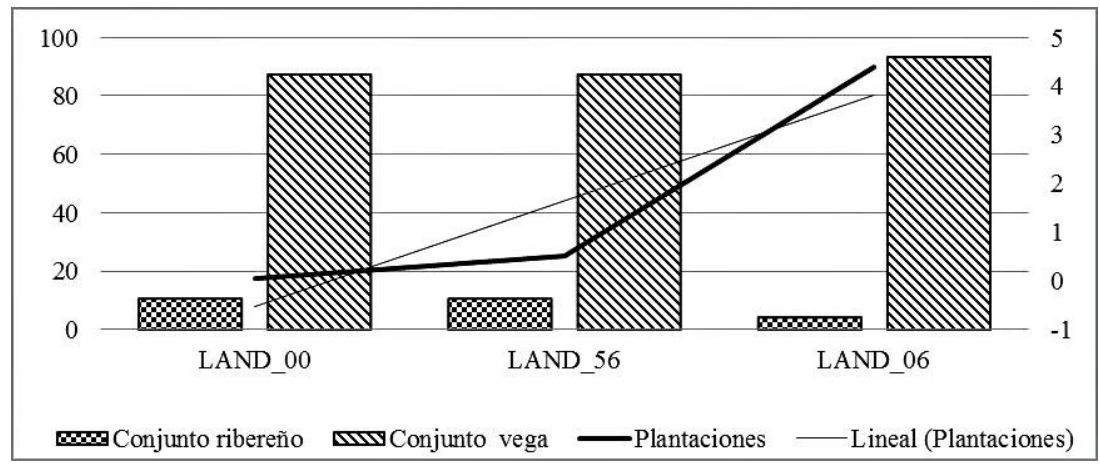

Elaboración propia.

\subsection{La restauración fluvial y la representatividad contenida del elemento forestal en las riberas del Pisuerga (1/2 del siglo XX)}

El primer escenario se corresponde con los inicios de la política hidroforestal en la cuenca del río Pisuerga, extendiéndose desde la década de los años veinte hasta principios de los cincuenta del siglo pasado. Según la documentación consultada, los primeros proyectos de repoblación realizados por la Confederación Hidrográfica del Duero tuvieron por objeto principal solucionar el elevado grado de deterioro que presentaban las márgenes fluviales. La merma progresiva de los taludes y la creación de canales sobre las tierras próximas eran dos de las problemáticas ambientales derivadas del esquilmo secular de la vegetación de sus riberas, del dragado de materiales aluviales y de la propia fuerza del río. Los ingenieros del Servicio Hidrológico-Forestal ${ }^{4}$ de la Confederación optaron por la recuperación integral de la masa vegetal de ríos y arroyos como principal medida restauradora. La reforestación de los taludes mejoraba la fijación del suelo, incrementando su resistencia ante las fuertes y recurrentes crecidas que experimentaba el río, apenas regulado en esas fechas (figura 2). Los informes previos sobre los espacios de susceptible forestación destacaban "la evidente urgencia de contener la labor destructora de la corriente", identificando y caracterizando "los trozos de márgenes que sufrían los efectos de la socavación y consiguiente desmoronamiento del terreno" (Proyecto de Repoblación y Fijación del Río Pisuerga en el Término Municipal de Melgar de Fernamental - Provincia de Burgos, 1929: 14-15).

Las manchas de frondosas introducidas se localizaron en los terrenos correspondientes a la categoría de dehesas boyales ${ }^{5}$, los cuales eran habitualmente de propiedad comunitaria y estaban ocupados por pequeñas manchas arboladas. Según los inventarios de vegetación natural y seminatural incorporados en los proyectos forestales y otros informes agronómicos, en las áreas de condiciones más favorables se aglutinaban las formaciones arbóreas naturales con mayor densidad y complejidad, compuestas por taxo-

4 Figura creada por el Real Decreto de siete de julio de 1907 con el objetivo de desarrollar las medidas oportunas para la protección y defensa contra las inundaciones y los aterramientos de vegas, poblados y vías de comunicación, vidas y bienes rurales, mediante los trabajos de restauración forestal de las cuencas de los ríos y la corrección de sus cauces (Ley de 18 de Octubre de 1941), sobre repoblación forestal de las riberas de ríos y arroyos, BOE/ Boletín Oficial del Estado, nº 350, p.9823.

5 Definidos como bienes comunales del municipio adquiridos por compra al Estado y declarados posteriormente como dehesas boyales, según el Proyecto de Repoblación y Fijación de Márgenes del Río Pisuerga en el Término Municipal de Melgar de Fernamental Provincia de Burgos (1929). Fuente: Archivo General de la Confederación Hidrográfica del Duero, nº110, C/00037/4. 
nes de Populus alba, Populus nigra, Ulmus minor, Fraxinus angustifolia y una orla arbustiva dominada por individuos el género Salix. En el resto de zonas predominaba un tapiz arbustivo y herbáceo heterogéneo, compuesto por especies dispuestas según la humedad edáfica del terreno y la presencia más o menos determinante de la actividad humana. En las praderas más húmedas dominaban las gramíneas del género Elymus y Brachypodium, y en las áreas con el sustrato aluvial próximo, distintos ejemplares de juncáceas y leguminosas. Por su parte, los sectores más secos y contiguos a la vega mostraban un dilatado listado de herbáceas de naturaleza ruderal y arvense, como Caucalis daucoides, Anchusa itálica, Ononis campestris, Onopordon acanthium, Cirsium vulgare, Sonchus arvensis, etc.

Junto a las cuestiones ambientales, tanto las corporaciones locales (Ayuntamiento y Juntas Vecinales), como los particulares responsables de la gestión y la conservación de estos espacios, pretendían dotar de un cierto valor productivo a estos espacios libres y aparentemente incultos. El objetivo era generar una alternativa a la explotación agropecuaria dominante, especialmente al cultivo de cereal de secano, actividad primordial de las economías locales. Los espacios potenciales para la forestación se definían por sus especiales condiciones edafológicas (canturriales) y de dinámica fluvial (inundaciones periódicas/ freático elevado), que disminuían significativamente los valores de calidad agrológica. Las memorias de reconocimiento de los primeros proyectos de repoblación se hicieron eco de todas estas cuestiones ambientales y socioeconómicas como justificación principal para su aprobación y desarrollo (Proyecto, 1929: 11):

"Los terrenos de márgenes del Pisuerga en la zona que nos ocupa, son de formación aluvial en la que abundan las arenas y arcillas, es decir, que son aluviones relativamente modernos (...), predominando los suelos empradizados sobre los exclusivamente cascajosos. La humedad propia de su situación en las proximidades del río de caudal constante y la que proviene de un régimen de lluvias comprendido entre los 500 y $600 \mathrm{~mm}$ (...), hacen que esta clase de suelos sean excepcionalmente aptos para el desarrollo de las especies de crecimiento rápido".

Figura 2. Ejemplo de los primeros proyectos hidroforestales en el río Pisuerga durante la primera década del siglo XX.

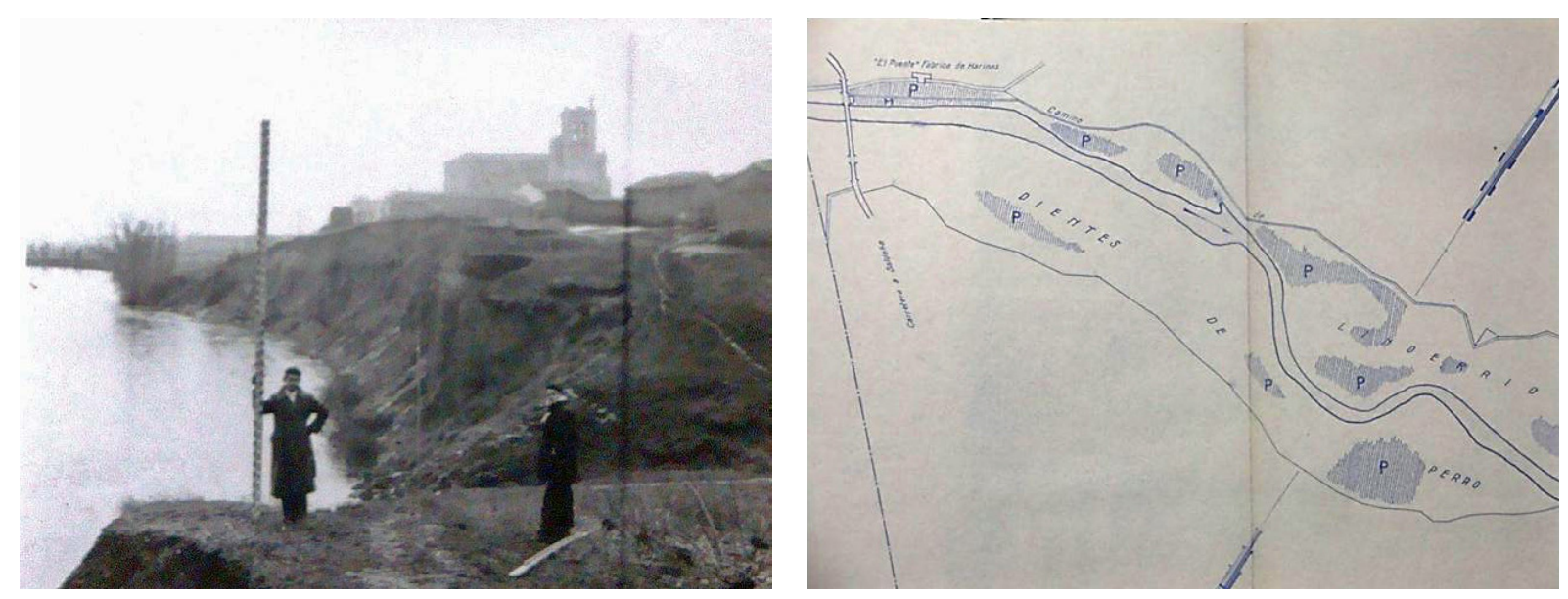

A la izquierda, fotografía adjunta en el Proyecto de Defensa contra el río Pisuerga de Lantadilla (Palencia), 1948. Fuente: Archivo General de la Confederación Hidrográfica del Duero, No 1471, C/00360-4. A la derecha, un croquis de las primeras manchas de repoblación en las márgenes del curso medio durante el primer tercio del siglo XX. Fuente: Confederación Hidrográfica del Duero. Archivo General, $\mathrm{N}^{\mathrm{o}} 110, \mathrm{C} / 00037-4$.

La construcción adicional de infraestructuras de contención y protección completaban los trabajos de restauración fluvial. Entre los distintos tipos de construcciones destacaron, por el número y el impacto sobre las márgenes, las corazas, los espigones transversales, los muretes de defensa y los gaviones metálicos rellenos de cascajeras y depósitos de álveo del propio río. En el núcleo de Lantadilla (Palencia), el desmoronamiento del talud derecho del río a su paso por el sector de las huertas, como consecuencia de la incisión directa y continuada del agua, hizo necesaria la construcción de varios de estos espigones laterales (figura 2). Con el mismo tipo de equipamiento se protegió la margen izquierda del núcleo de Itero de la Vega décadas después (1963), como solución principal a las fuertes riadas que continuaban arrasando la vega próxima. 


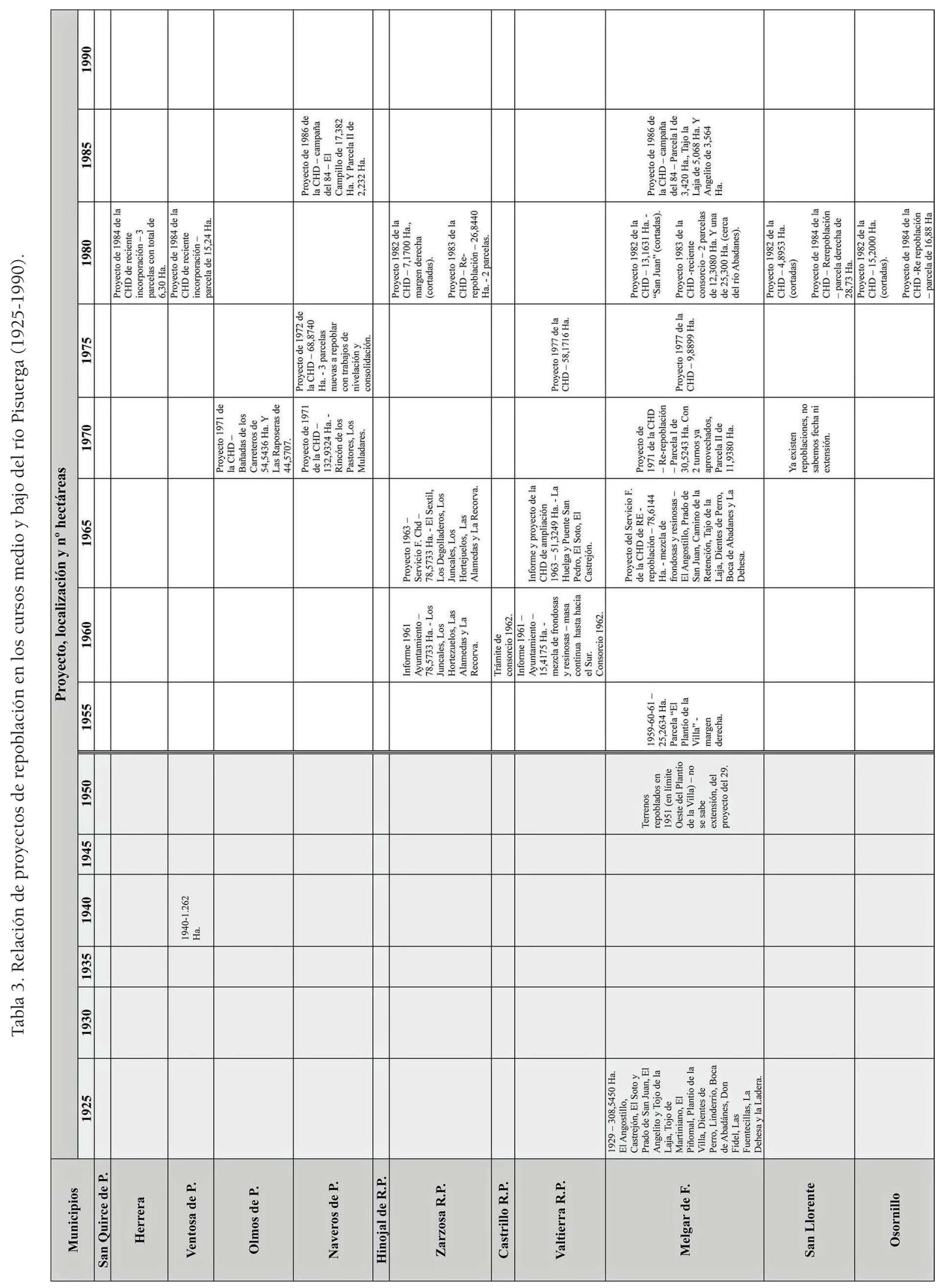




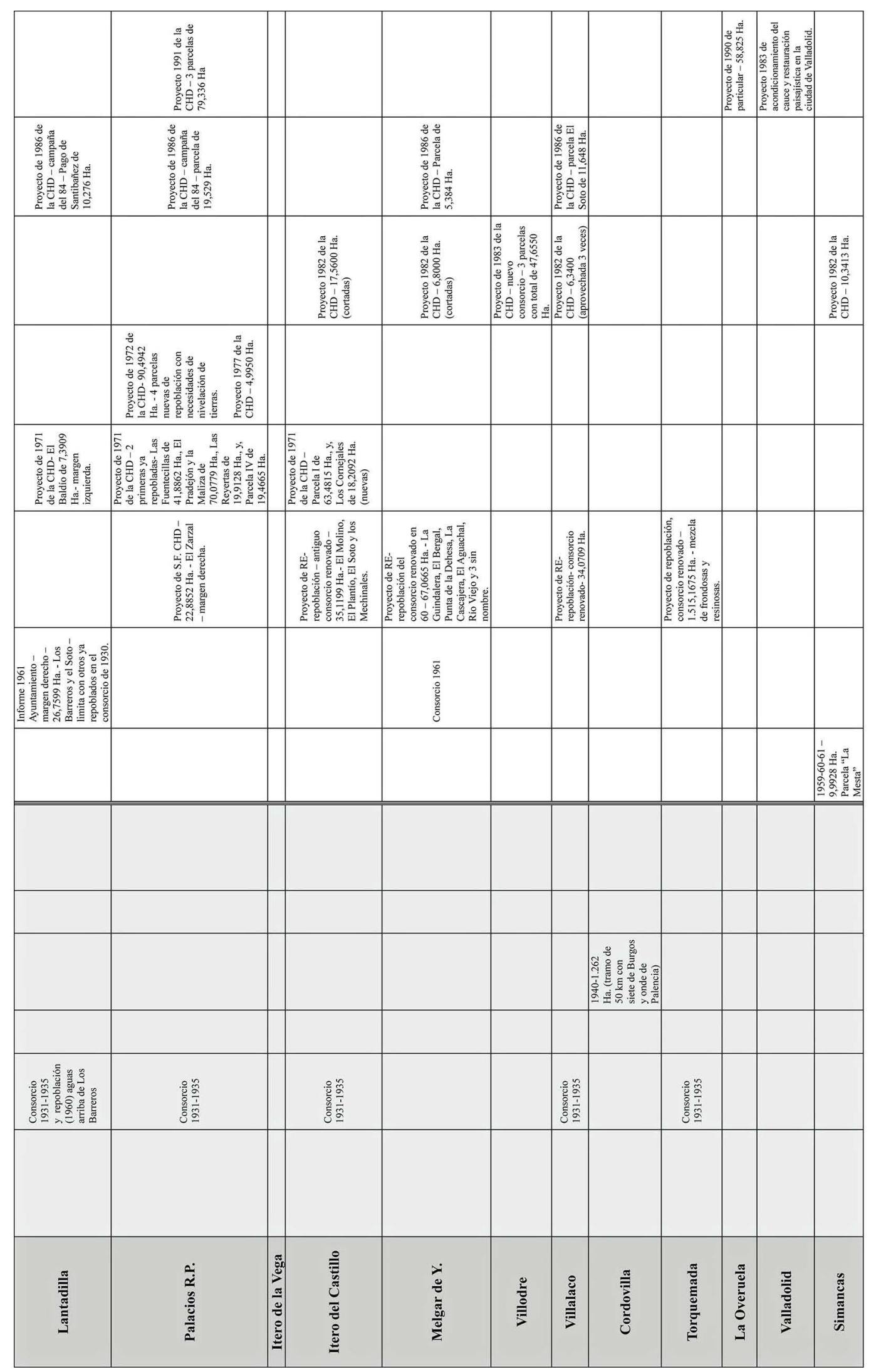


Tabla 4. Evolución de los índices de representatividad, superficie y variabilidad de la cobertura de "plantaciones" entre 1900 y 2006.

\begin{tabular}{|c|c|c|c|}
\hline & Plantaciones_00 & Plantaciones_56 & Plantaciones_06 \\
\hline \%LAND & $1,46 \%$ & $1,93 \%$ & $7,87 \%$ \\
\hline NP & 88 & 140 & 142 \\
\hline MPS & 91,09 & 90,95 & 27,21 \\
\hline
\end{tabular}

Elaboración propia.

Las dimensiones y los efectos territoriales de los primeros "consorcios" fueron todavía limitados en esta etapa inicial, tanto en el número y la extensión de los trabajos, como en la localización espacial de los mismos. Los "consorcios" eran contratos privados suscritos entre el propietario del terreno - Ayuntamiento, Junta Vecinal o particular - con la administración forestal, en los que se establecían las distintas tareas, derechos y obligaciones de cada una de las partes implicadas. La administración forestal competente era responsable exclusiva de la plantación, el mantenimiento y la corta de las mismas, sin generar coste alguno para los propietarios, los cuales mantenían la posesión del terreno en todo momento. Con posterioridad a la corta, los beneficios alcanzados se repartían en porcentajes del $60 \%$ para la administración forestal y del 40\% para el propietarios (Ley de 1941). Sin embargo, estos porcentajes podían variar ligeramente (50\%-50\%), atendiendo a las aportaciones hechas por ambas partes durante el proceso o por la determinación de requerimientos especiales aceptados de mutuo acuerdo. La evolución de los "Índices del paisaje" sobre representatividad (LAND), superficie (MPS) y número de fragmentos (NP) recogidos en la tabla 4 cuantifica el significado todavía restringido de las primeras choperas consorciadas (Plantaciones_00). Las nuevas masas de frondosas participaban como actividades complementarias en las economías locales y como elementos de diversificación relativa en el mosaico ribereño. Su presencia aportaba valores de frondosidad y compactación superiores a los del bosque de ribera, modificando parcialmente la imagen heredada del paisaje ribereño.

El análisis espacial a lo largo del valle refleja también el carácter sectorial de los proyectos iniciales, destacando el curso medio y medio-bajo del valle como principal ámbito de repoblación (tabla 3). Las primeras choperas de Populus sp.- género dominante en los "plantíos" - se concentraron en el entorno de núcleos como Palacios de Riopisuerga, Lantadilla, Itero del Castillo, Simancas o Melgar de Fernamental. Éste último puede ser considerado como el foco pionero del aprovechamiento forestal en las riberas del Pisuerga, con la aprobación en 1929 del Proyecto de Repoblación y Fijación del Río Pisuerga en el Término Municipal de Melgar de Fernamental - Provincia de Burgos. La oferta de una extensión considerable de terreno por parte del Cabildo (300 ha en 15 fincas) y la existencia previa de dos viveros en su término fueron sus principales atractivos. Así lo recogen los Preliminares de dicho Proyecto, redactados por el Servicio Forestal de la Confederación Sindical Hidrográfica del Duero en 1929 (1-2):

"La razón de ser el término de Melgar de Fernamental el primero en que se propone la realización de trabajos, estriba en que habiéndose dirigido solicitándolos en instancia al Delegado Regio de la confederación aquél Ayuntamiento, se vio, por el reconocimiento practicado, que poseía una considerable extensión de terreno muy apropósito para iniciar los trabajos y que además existían ya dos trozos de vivero que podían servir de base para la repoblación".

Figura 3. Evolución general y por tramos del índice de core area o hábitat interior relativo a la cobertura de "plantaciones" entre 1900 y 2006.

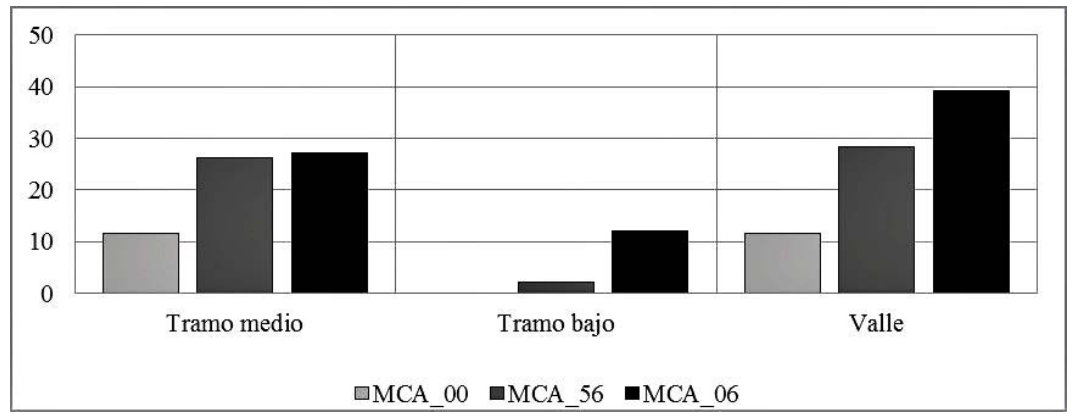

Elaboración propia. 
La dinámica repobladora mantuvo un comportamiento similar en décadas posteriores, mediante iniciativas análogas como el Proyecto de Repoblación y Fijación de márgenes del Pisuerga de 1931. Entre 1929 y 1940, el promedio hectáreas repobladas fue de 785,27 ha en todo el valle, cumpliendo con las expectativas estimadas por la Confederación en los inicios de la estrategia forestal. Tan sólo unos años después, el ritmo y la extensión de los trabajos se incrementó exponencialmente. La incorporación de estos espacios al Patrimonio Forestal del Estado en 1939 determinó su evolución y su caracterización en el mosaico paisajístico durante la segunda mitad del siglo XX.

A pesar de los bajos índices de representatividad (LAND) y potencialidad (MCA) de la cobertura forestal en su etapa inicial, la presencia de este tipo de aprovechamientos generó las primeras consecuencias ecológicas y paisajísticas vinculadas con el avance definitivo del componente humano en el mosaico ribereño (figura 3). La variable natural se relega a un segundo plano, tanto en la localización, como en la organización interna de los "plantíos". El carácter planificado y geométrico de la trama y los bordes de las nuevas manchas forestales provocaron los primeros indicios de simplificación de las márgenes fluviales. Esta evolución - representada en la figura 4 - supuso el incremento de los valores de complejidad o "dimensión fractal" (AWMPFD) de las coberturas de repoblación forestal, frente a la reducción en los sectores colindantes ocupados por "sotos" y "sotos abiertos". Pese a ello, el carácter cuasinatural de las primeras choperas, las cuales derivaban en su mayoría de antiguos sectores de aprovechamiento forestal, contuvieron la pérdida de complejidad estructural del conjunto ribereño, acelerada décadas después. La morfología de las manchas forestales adaptada a la topografía del terreno - con trabajos de sistematización todavía de baja intensidad - atenuó parcialmente la cuadrícula en la que se disponían los plantones.

Figura 4. Evolución comparada de los índices MPS y NP del conjunto paisajístico de vegetación natural y seminatural de ribera con el índice de complejidad morfológica (AWMPFD) entre 1900 y 2006.

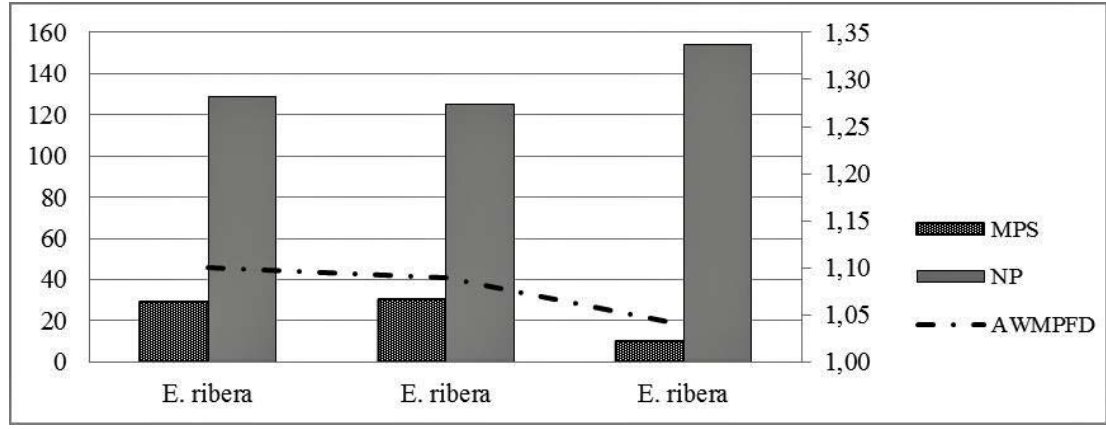

Elaboración propia.

La presencia de las primeras choperas generó también los primeros procesos de fragmentación en el corredor ribereño, aunque con valores poco significativos para el conjunto paisajístico en esta primera etapa (figura 4). El patrón espacial de las choperas presentaba un carácter puntual e intermitente entre las distintas masas forestales naturales y seminaturales identificadas, concentrándose en sectores concretos, como el curso medio en torno al núcleo de Melgar de Fernamental (figura 2), o en el último tramo del río, próximas a la localidad de Simancas (tabla 3). Los valores de los índices de configuración espacial - IJI, MNN y MPI - cuantifican esta evolución inicial. La localización adicional de un listado heterogéneo de equipamientos en el corredor ribereño, tales como casetas, puentes, caminos, etc., reforzaron las dinámicas de fragmentación y disgregación del conjunto natural.

En materia de composición, las primeras choperas promovieron una planificación ajustada parcialmente a criterios naturales. Las especies se seleccionaron de acuerdo con la naturaleza del suelo y el uso estimado tras su corta, utilizando taxones propios del ámbito ribereño. Esta práctica aportó, o más bien retuvo, cierto grado de naturalidad en el mosaico paisajístico hasta mediados del siglo XX. El chopo castellano (Populus nigra) y el lombardo (Populus pyramidalis) ocuparon los suelos más arenosos y cascajosos donde lograban un buen nivel de crecimiento. En las áreas de matriz más arcillosa se empleó el álamo (Populus alba), destacado por la calidad de su madera para la elaboración de mobiliario. Por último, en los suelos de mejor calidad la especie elegida fue el Populus euroamericana, especie catalogada por los ingenieros como la mejor para la producción de papel y desenrollo. También se incorporaron, aunque en menor número y con carácter secundario, el olmo o álamo negro (Ulmus campestris), el aliso (Alnus 
glutinosa) y diversas especies del género Salix (Salix alba y Salix purpurea). Estas últimas solían utilizarse como complemento de las obras de contención, localizándose longitudinalmente en las partes inferiores de los taludes: "el Salix alba (...) debe ser tomada en consideración para repoblar aquellas partes que con facilidad son inundadas y para formar con ellas cordones de vegetación que proteja las partes bajas de los taludes de las márgenes" (Proyecto 31/1940: 4).

Figura 5. Proyecto de repoblación forestal en la cuenca del Duero - término municipal de Olmos de Pisuerga y otros (Palencia y Burgos) (1971).

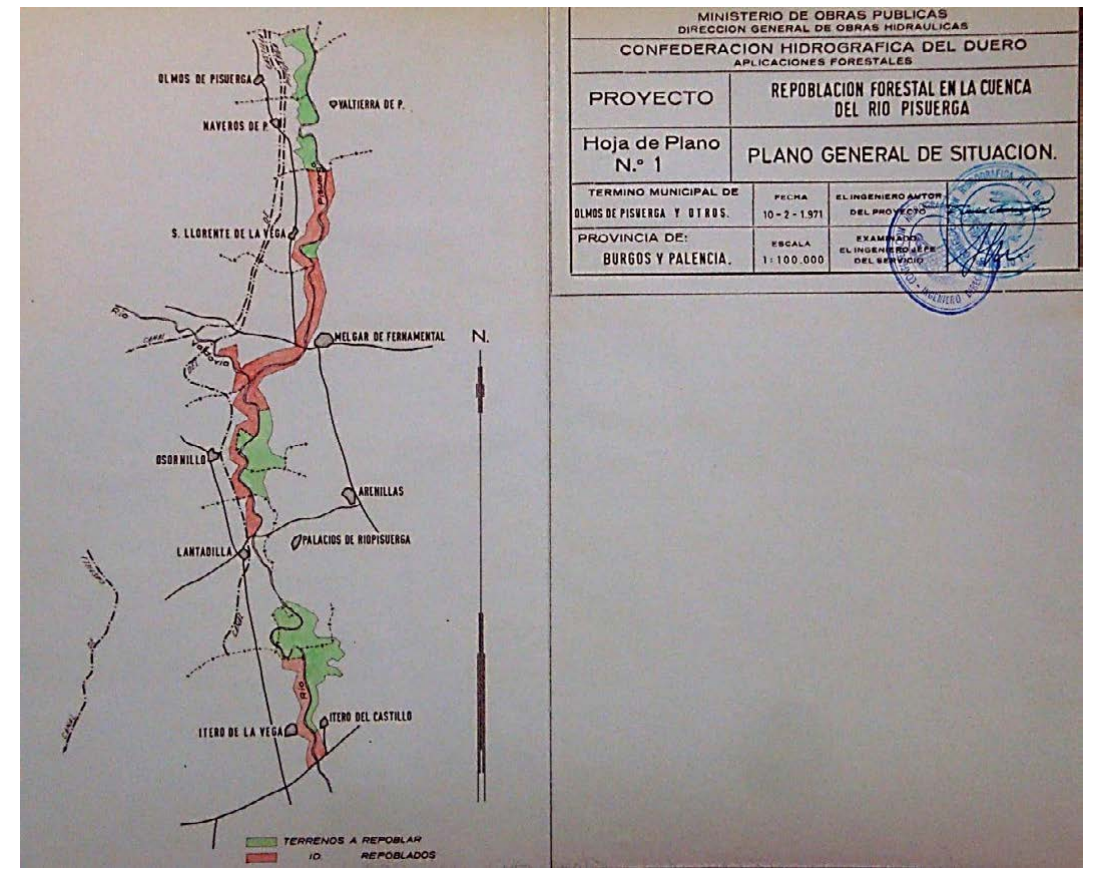

En color rojo, los sectores ya consorciados y repoblados, y en verde los terrenos de futura plantación. Se dibuja un «continuo forestal» a lo largo del río, afectando especialmente al tramo medio.

Fuente: Archivo General de la Confederación Hidrográfica del Duero, № 5405, C/01187-3.

\subsection{La expansión y la intensificación de la populicultura en las riberas del Pisuerga. El "continuo forestal" (1950-1990)}

Entre 1950 y 1990, el número y la extensión de los consorcios se incrementaron exponencialmente en las riberas del Pisuerga (tabla 3). Este aumento significativo de la superficie forestada, nueva o de primera renovación, respondía a dos circunstancias fundamentales: por un lado, la liberación masiva de terrenos por parte de Ayuntamientos, Juntas Vecinales y progresivamente de particulares, y por otro, la existencia de un marco institucional y legislativo favorable, a partir de la aprobación de la Ley de 18 de octubre de 1941 sobre repoblación forestal de las riberas de río y arroyos. La buena aceptación que mostraba el aprovechamiento forestal en el ámbito fluvial, como "medio para obtener saneados rendimientos de estos bienes patrimoniales (...) incapaces en muchos casos de cumplir misión física y económica" (Ley 18 octubre 1941), y la correcta coordinación con los trabajos de concentración parcelaria, bajo la promoción de "tierras excluidas" para choperas, fueron los principales factores de promoción del "continuo forestal". Además, la actividad se amplió a otros sectores del valle, en especial a zonas de terrazas medias y altas a través de la plantación de resinosas, y a las inmediaciones de los principales canales de riego (por ejemplo, el Canal del Pisuerga - plantación lineal de frondosas en Lantadilla -7,5 km - Proyecto de Repoblación Forestal en los canales del Páramo, Pisuerga y Villalaco, 1960).

"Con este proyecto queda completada la zona, sin discontinuidades que puedan tenerse en cuenta y con una ejecución quedará cubierta de arbolada la misma, con una distancia mínima de $27 \mathrm{~km}$ y con anchuras variadas que algún caso llegarán a los 1.100 metros" (Proyecto de Repoblación y Consolidación de las márgenes de Naveros y Palacios de Riopisuerga, 1972: 1-2). 
Los nuevos "plantíos" constituían una parte fundamental de la estrategia de fertilización y revitalización económica promovida por el régimen franquista en su intento por solventar los graves problemas del campo español. El objetivo final era consolidar, bajo el argumento del "interés nacional", una alternativa fuerte y duradera a la actividad agropecuaria dominante, estimulando la actividad industrial ligada a los recursos forestales (pasta de papel, construcción, energía, etc.) y reduciendo la presión de la crisis socioeconómica. En este sentido, el Servicio Forestal redactaba los informes pertinentes con alegaciones ligadas a "la producción de madera en terrenos marginales para la agricultura" (Proyecto de Repoblación en Valtierra, Melgar de Fernamental, Osornillo y Palacios de Riopisuerga, 1977:1), y la conformidad de los propietarios implicados en el proceso de contratación: "Todos los terrenos a repoblar que nos referimos en este trabajo son de propiedad de los respectivos Ayuntamientos o Juntas Vecinales que los vienen poseyendo quieta y pacíficamente, sin que hasta la fecha no haya presentado reclamación alguna" (Proyecto de Repoblación Melgar y Simancas, 1963:3).

En esta segunda etapa de "eclosión forestal" se pueden distinguir dos momentos claves en el devenir de la actividad y su papel en la evolución del paisaje ripario del Pisuerga. Los criterios de diferenciación están relacionados, no tanto con el objetivo consolidado de alcanzar un "continuo forestal" a lo largo del valle (figura 5), como con los aspectos más técnicos en materia de propiedad, especies, producción, etc.

\subsubsection{Redefinición del marco institucional e impulso de los grandes consorcios públicos (1950 -1970)}

En el punto álgido de las estrategias de revitalización y modernización que marcaron el devenir territorial de la cuenca del Pisuerga durante la segunda mitad del siglo XX, la política forestal experimentó un impulso definitivo como actividad productiva y como agente paisajístico en el mosaico ribereño. La importancia económica y social que obtenían los "plantíos" en el nuevo proyecto territorial suscitó el máximo interés de los agentes públicos - Confederación, Ayuntamientos y Juntas Vecinales - por ocupar todos los terrenos municipales desprovistos de aparente utilidad. Estos sectores de dominio público y dimensiones habitualmente destacadas, por su origen (bienes comunales) y su localización (áreas inundables), dieron lugar al desarrollo de los proyectos más grandes y de mayor trascendencia del proceso. El grueso de los trabajos aprobados durante este primer periodo de expansión alcanzó el 40\% de los terrenos consorciados durante el siglo XX (tabla 3). Los límites se dilataban significativamente sobre el espacio fluvial, difuminando incluso las demarcaciones municipales. Las dimensiones de los paquetes de tierra ofertados oscilaban entre las 20 y 80 ha, distribuidas en ambos márgenes del río, sobre suelos de origen cuaternario (zonas de aluvión) y dotadas con infraestructuras de riego de calidad contrastada. La búsqueda de la "continuidad forestal" - como representación del objetivo fertilizador - era el fundamento de peso entre las directrices y los requisitos recogidos en las peticiones y los proyectos de repoblación (figura 5).

Los municipios más pequeños y con menores posibilidades de desarrollo fueron los primeros interesados en la cesión de sus terrenos comunales, especialmente los ubicados en el curso medio y medio bajo del río (Olmos de Pisuerga, Naveros de Pisuerga, Valtierra de Pisuerga, Zarzosa de Riopisuerga, Palacios de Riopisuerga, Lantadilla, Itero del Castillo, Osornillo, Villalaco) (tabla 3). Pese a que la extensión por consorcio municipal era relativamente menor en esta parte del valle, los proyectos tendieron a desarrollarse de forma conjunta por partidos judiciales y optando por grandes extensiones: "Si bien no es grande la superficie de los terrenos ofrecidos, debe tenerse en cuenta su posición entre los terrenos, muy próximos, consorciados con Melgar de Fernamental y Zarzosa de Riopisuerga (...) que llegarían a formar una masa casi continua, desde Lantadilla hasta Zarzosa, con una superficie muy aproximada a las 600 ha, todas ellas de frondosas" (Proyecto de Valtierra de Río Pisuerga, 1961). En el curso bajo, por su parte, el número de consorcios aprobados fue menor en este primer periodo, aunque con un tamaño importante cada uno ellos, lo que permitió mantener el ritmo de construcción del "continuo forestal" iniciado aguas arriba; núcleos como Torquemada llegaron a ofertar terrenos por encima de las de 1.000 ha (Proyecto, 1963).

La intensidad de las directrices forestales renovadas se manifestaba, no solo en el incremento exponencial del número y la extensión media de los consorcios - en su mayoría de primera plantación - sino también en cuestiones técnicas, como el número de plantones por parcela, el tipo de cuadrícula, las especies seleccionadas y los "trabajos auxiliares" y "equipamientos de obra" requeridos a lo largo del proceso. El objetivo principal era la obtención de beneficios en plazos de tiempo más cortos que con otras especies, y fomentar la facilidad reproductiva de los individuos (JCyL, 1997:7). El espaciamiento entre pies se mantuvo en la mayoría de los proyectos, aunque se incrementaba la distancia progresivamente entre 
plantones, pasando de los tres o cuatro metros, con una densidad media de 500 plantones por hectárea, a cuadrículas de 4 a 8 metros con una densidad media de 300 a 400 plantones por hectáreas. El alto coste de los trabajos de limpieza y destoconamiento, la reducción de los jornales de riego y el aumento del periodo de crecimiento (más de 2 años) fueron los principales responsables del cambio. El turno de corta también experimentó modificaciones significativas. El intervalo de 20 años de los primeros proyectos se redujo en 4 años. Las constantes innovaciones en las tareas de repoblación, especialmente en las técnicas de riego (grupos elevadores) y en las especies utilizadas, ayudaron significativamente en este proceso.

Los criterios de selección de los plantones fluctuaban entre los estrictamente económicos y los ecológicos y biológicos, vinculados con la capacidad de crecimiento y de reproducción de la masa forestal en los terrenos escogidos. El peso de unos respecto de otros variaba en cada proyecto, aunque se mantenía una preferencia significativa por los aspectos mercantiles en todos ellos. El nefasto rendimiento económico obtenido de las plantaciones iniciales, caracterizadas por el manejo de especies propias de los ambientes ribereños (Populus alba, Populus nigra), reducían el listado de candidatos a una relación limitada de híbridos introducidos con orientación fundamentalmente productiva. El híbrido Populus canadensis o Populus euramericana Guinier fue la especie más apreciada, tanto para las choperas de Ayuntamientos y Juntas Vecinales, como para los plantíos de iniciativa particular. Sus clones más destacados, el "Cid Campeador, o variedad blanca, y el "canadiense negro", "negrito", o variedad negra, aportaban volúmenes de producción, tiempos de crecimiento y valores de resistencia habitualmente superiores al resto:

"En consecuencia, fijado también el factor económico, gran parte de la elección, en los híbridos euroamericanos, por su rápido crecimiento y por las demás características reseñadas, fijamos como especie para las repoblaciones de este proyecto" (Proyecto, 1963: 37)

"En cuanto a los diversos clones, teniendo siempre en cuenta al llamado negrito, que si bien es menor en su crecimiento, es más resistente a las heladas y plagas, presentando fustes limpios y rectos, así como madera de buena calidad muy apreciada para el embalaje normalizado (...)" (Proyecto, 1972: 18).

Los "trabajos auxiliares" adquirieron asimismo un carácter diferente en los nuevos proyectos forestales. Las obras de protección y contención perseguían el doble fin de favorecer el crecimiento de las especies plantadas y controlar la erosión masiva del suelo desprovisto de tapiz herbáceo: "complemento obligado de los trabajos de repoblación (...), es el de fijación de las márgenes mediante las mismas, que cumplirán un doble fin, primero proteger al joven arbolado (...), y segundo, evitar la formación de nuevos cauces...) (Proyecto, 1963: 50). La calidad técnica de los equipamientos e infraestructuras se incrementó de forma destacable, al igual que la intensidad de los impactos generados en el cauce y las márgenes fluviales con su construcción. La sustitución de las tradicionales saucedas arbustivas por mallas metálicas en las tareas de ataludamiento generaba cambios en el trazado del cauce e importantes implicaciones ecológicas y paisajísticas en el conjunto ribereño.

El impulso forestal alcanzó también las terrazas medias y altas del río, con la proliferación de pequeñas masas de Pinus pinaster y Pinus laricio en antiguas zonas de cultivo y de matorral para pasto. La dificultad de asegurar el riego en estos sectores declinó la posibilidad de repoblar con frondosas, no obstante, se obtuvieron buenos resultados de los plantíos de resinosas desarrollados en términos como Torquemada, con 253 ha de páramo repoblado, o en Melgar de Fernamental, con 8,93 ha en las terraza media del margen derecho, según el Proyecto de Repoblación de 1963.

\subsubsection{La "privatización" de las choperas y el estancamiento de la iniciativa pública (1980-1990)}

A finales del siglo XX, el continuo forestal estaba prácticamente culminado. Tras la intensidad y la expansión experimentada por el elemento forestal durante las dos décadas anteriores, especialmente bajo el impulso de las entidades públicas y la Ley de 18 de octubre de 1941, en los años ochenta y noventa la actividad forestal experimentó ciertos cambios en su comportamiento. Por un lado, el número de consorcios municipales de primera repoblación presentó un relativo estancamiento, primando las renovaciones de los existentes, y por otro, la participación particular limitada hasta el momento por el protagonismo del agente público, experimenta una tendencia al alza, tanto en el número, como en la extensión de los "plantíos" proyectados. La aprobación de la Ley de Montes de 1957 y la posterior Ley de Fomento de Repoblación Forestal de 1977 conformaron el marco legislativo de este segundo periodo.

Las relaciones entre la Confederación y los particulares mantenían requerimientos jurídicos similares a los consorcios municipales tradicionales, aunque con dimensiones más reducidas, que raramente supe- 
raban las 2 ha por parcela, excepto ejemplos concretos en Palacios de Riopisuerga con 8,05 ha o Valladolid con 9,75 ha (tabla 5). Aparecieron, además, nuevas fórmulas de contratación - los "convenios" - y se multiplicaron las ayudas y auxilios a particulares (Montero de Burgos, 1987: 29-30) .

El auge de la masa forestal consorciada de propiedad privada mostró dos tendencias principales a lo largo del valle. La primera afectaba nuevamente a los núcleos más pequeños y de economías más limitadas del tramo medio y medio alto, donde la disposición de terrenos particulares para usos forestales funcionaba como principal alternativa económica al campo y el agotamiento de terrenos comunales para nuevas choperas. La segunda tendencia se identificó en el curso bajo, donde el mayor protagonismo de los plantíos de propiedad particular era resultado de una limitada participación pública en la estrategia forestal y de una escasa necesidad de buscar alternativas económicas, en un contexto socioeconómico aparentemente más favorable que en el resto de sectores del valle. La influencia histórica de las principales vías de comunicación (Canal de Castilla, ferrocarril, carreteras, etc.), la presencia de un nivel de actividad industrial mayor y una agricultura más rentable y productiva (por ejemplo, huertas históricas de Torquemada y Valladolid) reducían aparentemente el peso de la actividad forestal en las economías locales del curso bajo (figura 6). El núcleo ribereño de Astudillo con 11 consorcios, y el de Soto del Cerrato y Baños de Cerrato con otros 8, fueron los casos en los que la figura privada dominó en la estrategia forestal de las últimas décadas del siglo XX (tabla 5).

Los consorcios con entes municipales experimentaron cierta ralentización en el número de hectáreas plantadas desde finales de la década de los años ochenta. La mayoría de consorcios aprobados correspondían a las renovaciones de los grandes consorcios municipales desarrollados durante los años 60 y 70 . La existencia de un elevado porcentaje de forestación en los terrenos de utilidad pública de las márgenes fluviales, especialmente en el tramo medio, y la dominante reciente del regadío en la vega colindante, apenas dejaban espacios libres para el desarrollo de nuevos "plantíos". Pese a ello, la oferta pública se mantenía en valores similares a acuerdos anteriores, con valores medios de 7 ha por superficie.

"Están todas las parcelas incluidas para la repoblación situadas en la cuenca del río Pisuerga, y excepto las parcelas de Pedrosa del Príncipe, que son incorporación reciente por nuevo consocio, fueron plantadas hace años y su arbolado cortado en campañas pasadas" (Proyecto de Repoblación en la Cuenca del Rio Pisuerga, 1982).

Para ambos tipos de consorcios, la técnica y la especie volvieron a adaptarse a las peticiones del mercado. El espaciamiento entre plantones mantenía la tendencia al esponjamiento iniciada en la etapa anterior. Los nuevos esquemas se centraban en plantaciones de tipo medio, con cuadrículas de 5 por 5 con 400 plantones por hectárea, y de 6 por 6 con 278 ejemplares por unidad de medida. El objetivo era conseguir fustes de mayores diámetros y mejor calidad que lograsen adaptarse a las necesidades del mercado: "En cuanto al espaciamiento de la plantación, la tendencia actual se dirige hacia una mayor amplitud, motivada por una mayor demanda en el mercado de árboles de mayores diámetros. Por ello, se ha elegido un espaciamiento de 6 por 6, equivalente a 277 árboles por hectárea" (Proyecto de Repoblación en los Ríos Arlanza y Pisuerga, 1986: 6).

El clon de Populus euramericana dominante durante este segundo periodo fue el "I - 214". Su elevado volumen de producción, su alta capacidad de resistencia y el bajo tiempo de desarrollo, reduciendo el turno de corta al intervalo de 10 a 15 años, impulsaron la renovación de los consorcios públicos y la aprobación de otros nuevos privados o particulares: "Las características del suelo hacen que nuestra elección se fije primordialmente en los híbridos euroamericanos, eligiendo entre los diversos clones existentes y de acuerdo con el estado de las repoblaciones al clon I-214" (Proyecto 01/82 de Repoblación forestal en la cuenca del Río Pisuerga: 4-5).

El destino del aprovechamiento forestal continuaba siendo esencialmente industrial, centrado en la producción de pasta de papel y madera en rollo. Entre los híbridos alternativos al "I-214" cabe destacar los ejemplares de "2000VERDE", "IMC", "I-488" y "NNVD". A mediados de la década de los noventa del siglo XX, el "NNVD", recientemente definido como "I-MC", presentaba un peso destacado en los plantíos particulares. El alto rendimiento del clon, la excelente calidad de su madera para desenrollo y la necesidad de cubrir extensiones de dimensiones más reducidas permitía utilizar estos ejemplares en las parcelas de particulares del curso medio y bajo.

6 En Valdés, 1996: 413-423. 


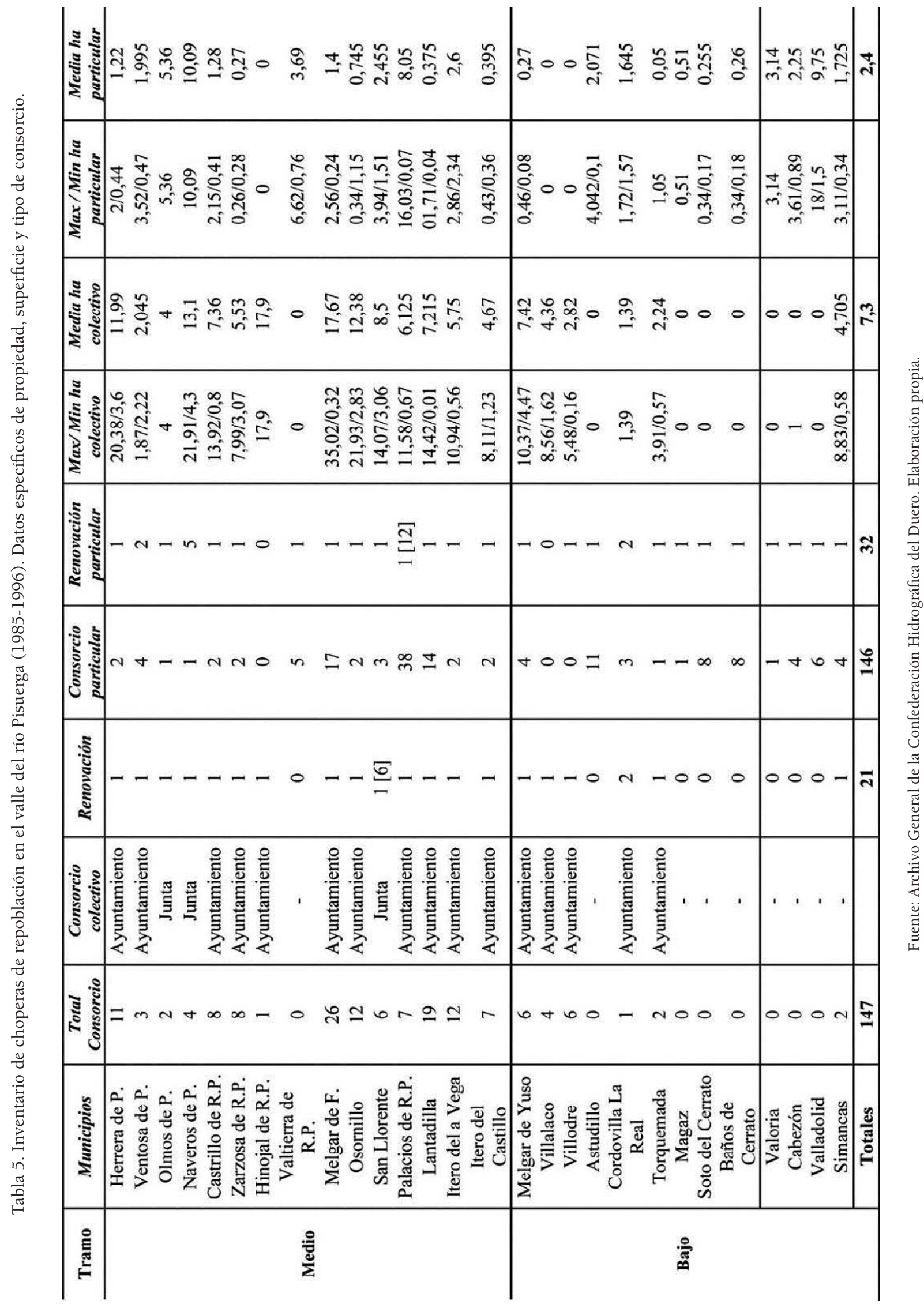


Figura 6. Mapa de localización de consorcios en el valle del río Pisuerga durante los años ochenta y noventa del siglo XX.

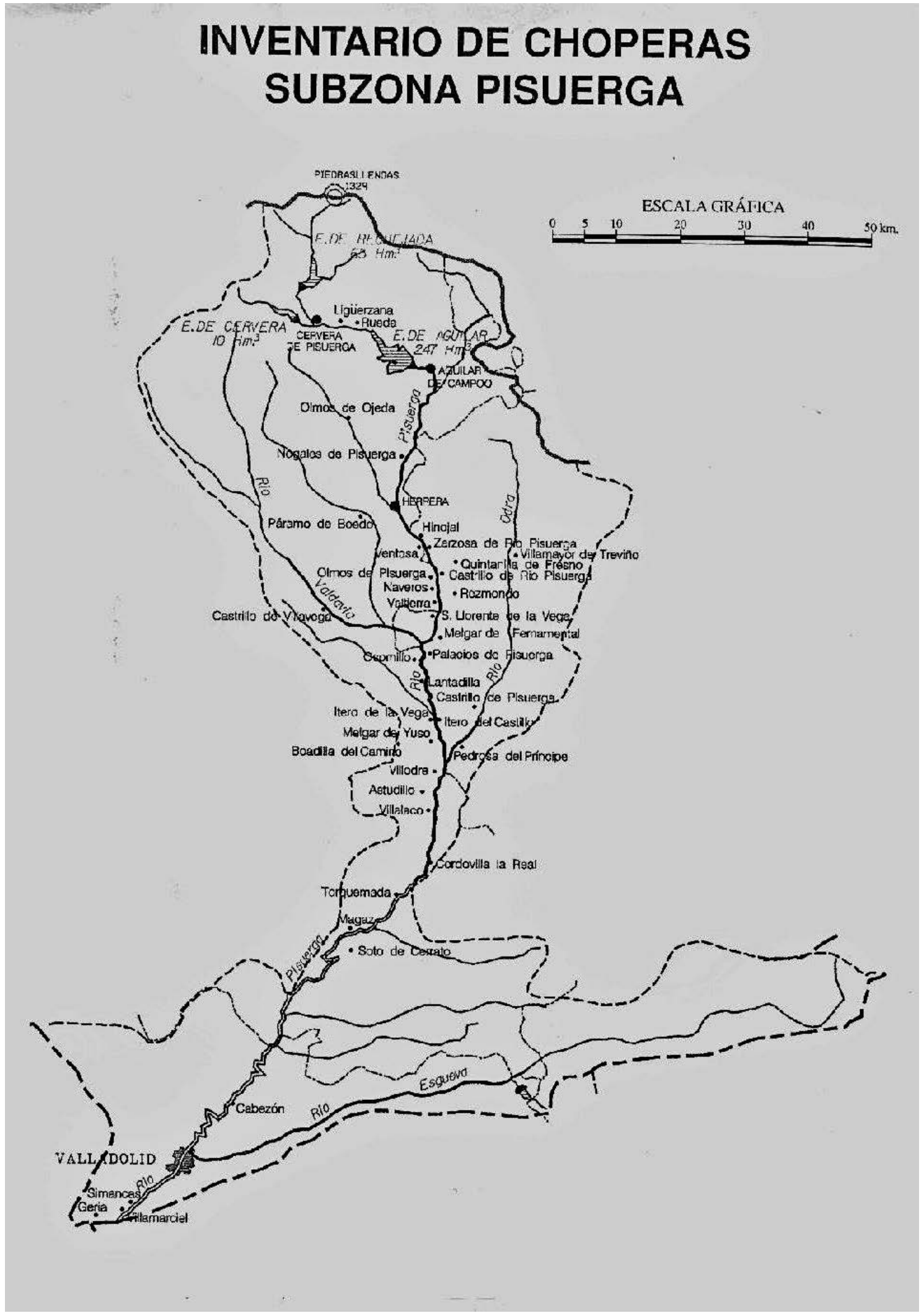

Atomización y expansión de la acción forestal, especialmente en el tramo medio del valle. Fuente: Archivo General de la Confederación Hidrográfica del Duero, sin información. 


\subsubsection{Implicaciones ecológicas y paisajísticas de la "eclosión forestal" en las riberas del Pisuerga}

Junto a la repercusión socioeconómica de las repoblaciones forestales en el valle del Pisuerga, el incremento exponencial de la superficie forestada generó importantes implicaciones ecológicas y paisajísticas en el paisaje ribereño de la segunda mitad del siglo XX, muchas de ellas persistentes en la actualidad. Entre 1950 y 1990, la dinámica continua e intensiva de ocupación de las márgenes fluviales por las masas de frondosas lograron consolidar el "continuo forestal" iniciado a principios de siglo. Los índices de representatividad paisajística (7,87 LAND), extensión (142 NP) y core area (MCA) cuantifican las dinámicas experimentadas por el nuevo mosaico forestal en esta etapa, el cual aparece progresivamente más denso, compacto y homogéneo (figura 3 y tabla 4).

Figura 7. Dinámicas de pérdida de representatividad, simplificación, fragmentación y desconexión del conjunto ribereño entre 1956 y 2006.

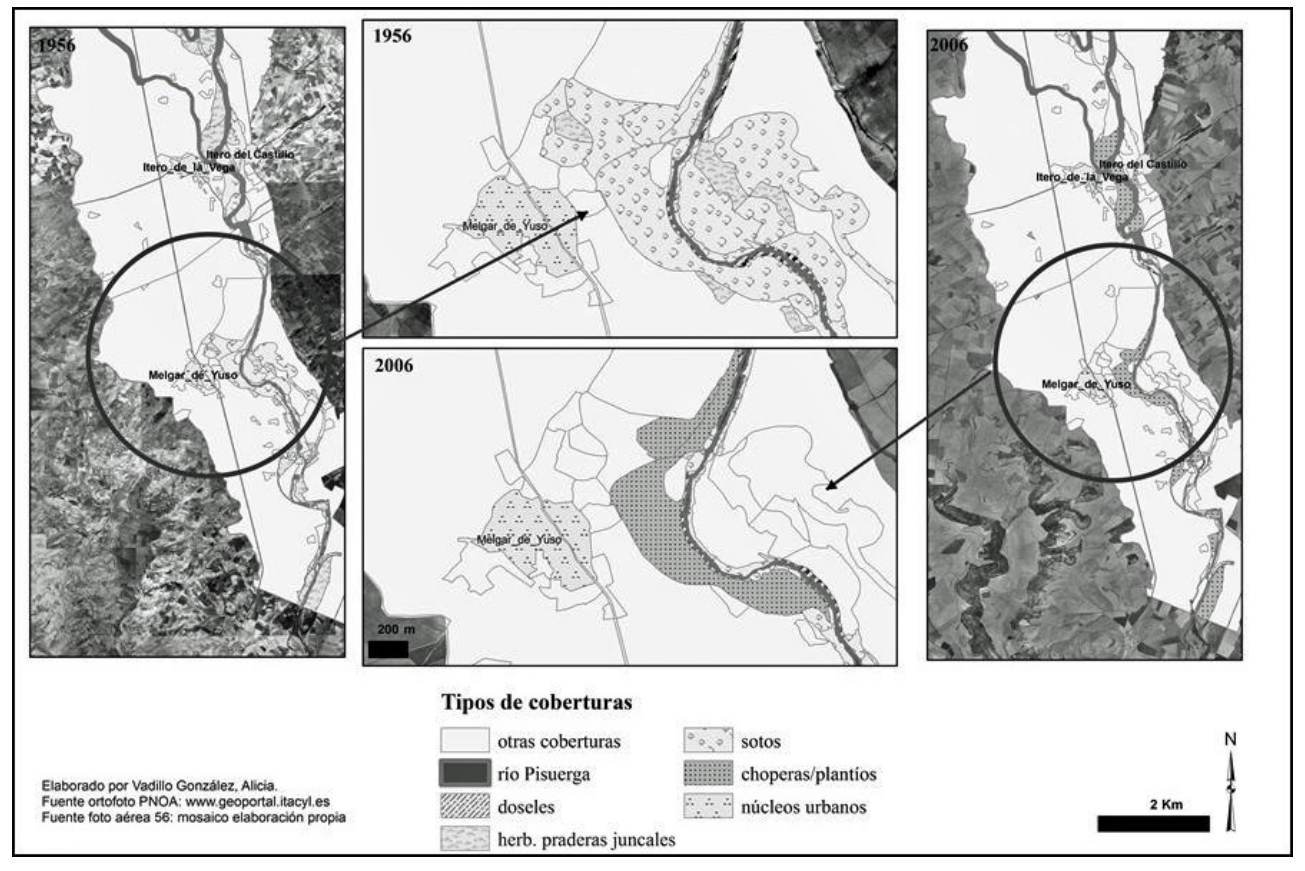

Fuente: http://www.geoportal.itacyl.es. Elaboracion propia.

La relativa brevedad y contundencia del proceso impulsó el avance de la frontera agro-forestal ("vega") sobre el espacio ribereño ("espacios de vegetación natural y seminatural de ribera"), con un ritmo y una intensidad superior al periodo anterior y una tendencia generalizada para el conjunto del valle. Esta intensificación en las dinámicas espaciales de simplificación, homogeneización y compactación ligadas a la presencia de las choperas controló la evolución del conjunto ribereño y sus formaciones vegetales en el último tercio del siglo XX, con morfologías y patrones espaciales distintos a los originales. El resultado del proceso fue un retroceso destacado de la línea ribereña, y con ello de los valores de core area calculados para el conjunto natural (figura 3), provocando la pérdida de ecosistemas de incuestionable valor y funcionalidad en el sistema natural del valle. Las formaciones de vegetación natural y seminatural que lo componían, fundamentalmente identificadas con las categorías de "sotos" y "praderas-juncales", fueron las principales afectadas por la estrategia forestal, evolucionando hacia estrechas franjas de vegetación residual, intensamente desestructuradas y con una composición empobrecida y homogénea (figura 7).

La expansión de los usos forestales en ámbitos ribereños generó también graves alteraciones en la configuración del patrón espacial ribereño de finales del siglo XX y sus relaciones con la vega. La ubicación de estas coberturas en el intervalo de 40 a 60 del índice de intercalado (IJI) ${ }^{7}$, y la reducción de las distancia entre vecinos (MNN), cuantifican la consolidación definitiva del "continuo forestal" en las riberas del Pisuerga. La dispersión inicial de los proyectos pioneros en las márgenes fluviales desapare-

7 Valores representativos de una abundancia media de choperas en el mosaico ribereño y un patrón de distribución del 50\%. 
ce, evolucionando desde mediados de siglo hacia un esquema más cohesionado físicamente, aunque no funcionalmente. La presencia de tramas planificadas, de trazado reticular y bordes abruptos dificulta las relaciones entre propios y vecinos (ribera/vega), en un fenómeno denominado como "contigüidad opaca", el cual ha favorecido la fragmentación y desconexión del ecosistema ribereño en su estructura interna y con su entorno agropecuario (figura 8). La pérdida de conectividad ecológica (Burel y Baudry, 2005; Gurrutxaga y Lozano, 2006) ha provocado la merma progresiva de las funciones vitales del ecosistema ribereño, como corredor y refugio biológico.

Figura 8. Dinámica expansiva de las choperas de repoblación (1956-2006). Retículas planificadas, composición homogénea y límites rectilíneos. Simplificación y desconexión del corredor ribereño.

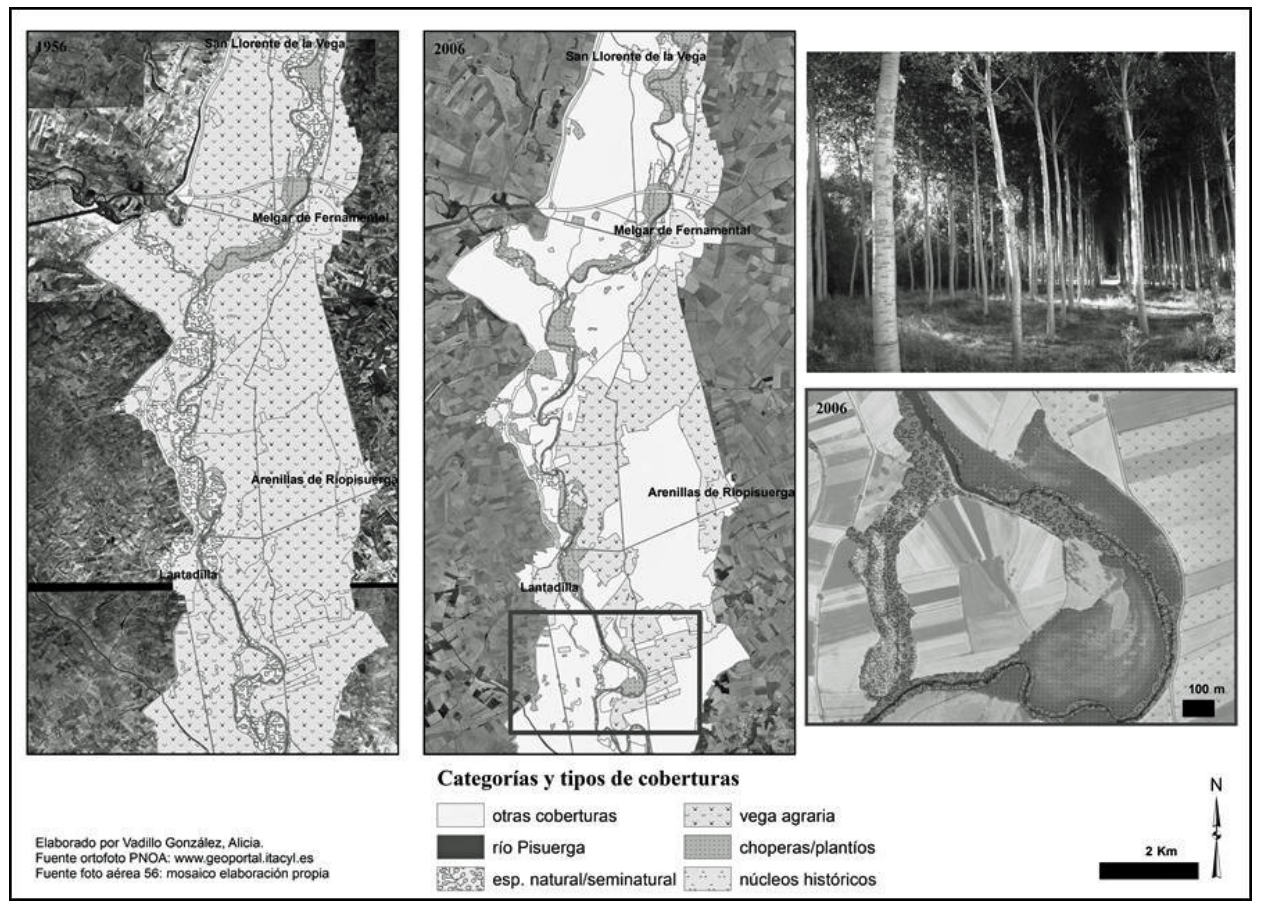

Fuente: http://www.itacyl.es. Elaboración propia.

Ante tales efectos negativos, la presencia de las choperas ha jugado un papel fundamental en la composición de la imagen paisajística de las riberas del Pisuerga. La anchura y continuidad de los "plantíos", y el contraste de la masa arbolada frondosa y casi permanente respecto a la vega cultivada, han dotado de una especial singularidad y diversidad a la imagen del paisaje de este valle castellano desde mediados del siglo pasado.

\subsection{Tendencias recientes e implicaciones de futuro. Recuperación del espacio ribereño. Naturaliza- ción y abandono de las choperas de repoblación}

Desde finales de la década de los noventa, el nuevo contexto de sostenibilidad ambiental en el que se fraguan las iniciativas actuales de ordenación del territorio, especialmente las vinculadas al ámbito rural, han modificado la base teórica y metodológica de la estrategia forestal en los tramos medio y bajo del Pisuerga. En unos casos, se opta por retomar la esencia de los proyectos de restauración fluvial primigenios, mientras que en otros se fomenta la búsqueda de alternativas productivas vinculadas esencialmente al sector de las energías renovables.

Los agentes públicos responsables de la política forestal también han experimentado cambios importantes. El traspaso relativamente reciente de las competencias productivas e industriales desde la Confederación Hidrográfica del Duero al organismo autonómico competente - la Junta de Castilla y León - ha supuesto una modificación sustancial del ente gestor de los consorcios. El nuevo Servicio Natural y de Aplicaciones Forestales de la CHD - antiguo Servicio Forestal - adopta nuevos retos en materia de conservación ambiental y restauración fluvial. La renovación parcial del contenido de los viveros ubicados 
en torno al curso fluvial es una de ellas, incrementándose el volumen de producción de especies propias del ámbito ribereño y otras dedicadas a trabajos de fijación de márgenes y restauración fluvial. Desde principios del siglo XXI, las reticencias del organismo a la renovación de los consorcios suscritos con las distintas entidades públicas, el abandono progresivo de los trabajos de mantenimiento de las masas de frondosas y la dilatación de los turnos de corta por razones diversas (disminución de precios, caída de rentabilidad, expansión de agentes privados, etc.) ha provocado importantes implicaciones ecológicas y paisajísticas en las riberas del Pisuerga. Las tasas de conectividad ecológica, de diversidad paisajística y de potencial ecológico experimentan ligeros síntomas de mejora con motivo de los procesos de incipiente naturalización de antiguos plantíos abandonados y la recuperación progresiva del espacio ribereño tras la corta y no renovación de los consorcios pertinentes. El resultado es la formación de una masa forestal seminatural más o menos continua y diversa, en la que junto a los doseles, sotos y praderas, aparecen nuevas formaciones de potencial valor ecológico y paisajístico a las que hemos denominado "choperas naturalizadas" y "sotos en regeneración" (figura 9).

Figura 9. "Choperas naturalizadas". Complejización progresiva de la estructura, incremento del potencial ecológico y mejora de la conectividad del corredor ribereño.

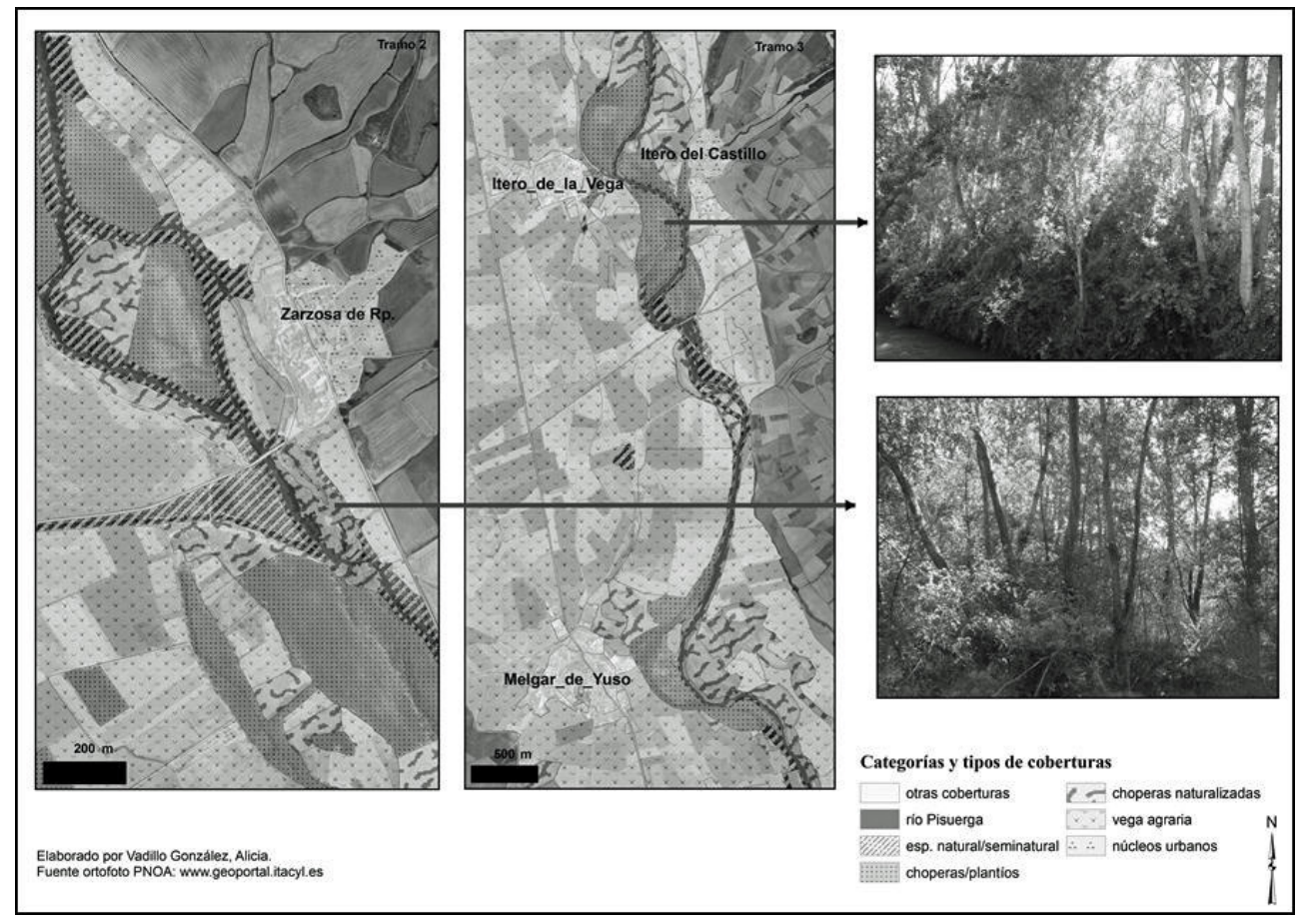

Fuente: http://www.itacyl.es. Elaboración propia.

Por su parte, la entrada del órgano autonómico en la gestión de las choperas y el incremento de la iniciativa privada, gracias a los continuos programas de incentivo promovidos desde la $\mathrm{UE}^{8}$, han contribuido significativamente en la configuración y la gestión reciente del escenario forestal del valle. La anexión de las plantaciones de chopo a la estrategia de desarrollo integral de la Junta de Castilla y León, mediante los Planes y Programas de Desarrollo Rural 2000-2006 y 2007-2013 cofinanciados por FEADER, responde a la batería de medidas y actuaciones adscritas al marco regulador europeo para potenciar y diversificar la actividad económica local. En este contexto, desde finales del 2009, se ha puesto en marcha un programa transversal de desarrollo del sector energético de la biomasa en Castilla y León, con la utilización de las choperas como principal fuente de suministro. Esta medida, vinculada con el Plan de Acción Europeo sobre Biomasa (PAB 2005), tiene como principal resultado la puesta en marcha del Plan Regional de

8 Reglamentos comunitarios vinculados a la Política Agraria Común (PAC), Reales Decretos y otros documentos legales donde la forestación aparece como principal acompañamiento a la actividad agraria (RG N²080/92, No 1610/89, RD 378/1993, Ley de Fomento de la Producción Forestal 5/1977, Agenda 2000, RD 6/2001). Tanto para el periodo 1992-1999, como para el 2000-2006, se contemplan subvenciones para fomentar las repoblaciones en régimen privado (Padró, 2003). 
Ámbito Sectorial de la Bioenergía de Castilla y León (PBCyL 2011). Las nuevas choperas para biomasa proliferan por las riberas del Pisuerga, extendiéndose progresivamente a sectores adyacentes de la vega, con cambios relevantes que afectan a aspectos técnicos, con turnos de corta inferiores a los 10 años y la utilización del regadío por goteo, como a los efectos ecológicos y paisajísticos producidos hasta ahora en el paisaje ribereño (figura 10).

Figura 10. Imágenes de las primeras "choperas energéticas" en el valle del Pisuerga (Osornillo, Palencia).

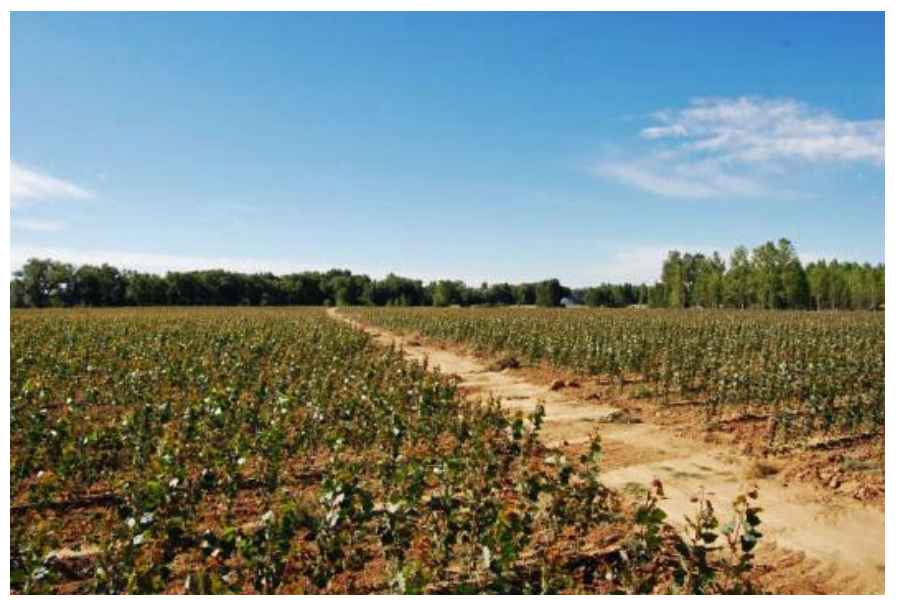

Fotografía de la autora.

\section{CONLUSIONES}

La elaboración de un análisis integrado de la información encontrada en las fuentes históricas, con los datos estadísticos obtenidos a través de los inventarios de vegetación y el análisis de los parámetros de paisaje, nos han permitido confirmar el papel de las repoblaciones forestales como elemento y factor clave en la composición y la configuración del paisaje de las riberas del Pisuerga durante el siglo XX y principios del XXI. La correlación de los resultados obtenidos en las distintas cesuras temporales pone de manifiesto que la dinámica espacial de las choperas o "plantíos" en las márgenes fluviales, y su mayor o menor protagonismo en el mosaico paisajístico, responden a cuestiones ambientales, socioeconómicas y culturales diversas, relacionadas directa o indirectamente con el contexto territorial particular en el que se insertan. El análisis de la evolución histórica, mediante tres escenarios temporales diferentes, ha sido determinante en el conocimiento de los tiempos y las intensidades adoptados por el proceso forestal en los tramos medio y bajo del río, en el papel jugado por los agentes implicados, el tipo de propiedad y gestión - públicos y particulares -, así como de los patrones de transformación observados en el esquema heredado de finales del siglo XIX.

El cambio identificado en los factores de control de estos paisajes durante la pasada centuria, especialmente acentuado desde la década de los años cincuenta, se encuentra directamente relacionado con el peso creciente de la acción humana sobre la base natural, así como con la orientación de las directrices tomadas por la estrategia forestal en cada uno de los periodos analizados. Mientras en los inicios del siglo $\mathrm{XX}$, la restauración y la fijación de márgenes marcaban la tendencia de los proyectos realizados, a mediados de éste, la progresiva regulación del hidrosistema, la implantación de un modelo de desarrollo territorial productivista, el avance de la frontera agrícola y la consolidación de una percepción renovada sobre el río y sus riberas, como elementos incultos de susceptible explotación, conformaban el marco territorial en el que se han fraguado los paisajes de ribera actuales. El corredor ribereño, compuesto por formaciones de vegetación natural residual - sotos, doseles y praderas -, se rompe y reduce sustancialmente con la entrada de la nueva masa forestal, provocando la degradación y la pérdida de funciones ecológicas y paisajísticas esenciales para el correcto funcionamiento de los ecosistemas asociados.

En los albores del siglo XXI, el giro de las políticas de ordenación y gestión del territorio hacia planteamientos más sostenibles y favorables a la conservación ambiental, está provocando la modificación parcial de los esquemas, las técnicas y las especies utilizadas durante las últimas cinco décadas. La incor- 
poración de nuevos valores e imágenes al paisaje de ribera, y la consolidación de intereses económicos y políticos renovados procedentes de los distintos ámbitos de gestión del territorio, han permitido redirigir parte de la actividad forestal hacia otro tipo de acciones, especialmente la restauración fluvial y el abastecimiento de sectores productivos alternativos. El abandono reciente de antiguas choperas y la menor renovación de los consocios establecidos en el último tercio del siglo XX complementan este nuevo contexto, en el que se vislumbran ciertas mejoras en las tasas de complejidad, diversidad y conectividad ecológica del corredor ribereño. Sin embargo, el cambio de dirección en la estrategia forestal ha generado otras implicaciones vinculadas con la expansión de las "choperas energéticas" o para biomasa. La búsqueda de alternativas económicas, supuestamente más sostenibles, para el desarrollo de áreas de dominante rural y agropecuaria, como el valle del Pisuerga, están desembocando en un proceso de incipiente invasión y alteración del mosaico paisajístico y de la imagen de complejidad y continuidad forestal proyectada. Los nuevos requisitos técnicos y el avance progresivo de este tipo de plantíos, incluso hacia la vega, están provocando ya importantes alteraciones en los paisajes de este valle castellano.

\section{REFERENCIAS}

Bethemont, J. (1980). Geografía de la utilización de las aguas continentales. Barcelona: Ed. Oikos-Tau.

Burel, F. \& Baudry, J. (2002). Ecología del Paisaje. Conceptos, métodos y aplicaciones. Madrid: Ed. en español. Mundi - Prensa.

Burel, F. \& Baudry, J. (2005). Habitat quality and connectivity in agricultural landscapes: the role of land use systems at various scales in space and in time. Ecological Indicators, 5, 305-313. doi: http://dx.doi. org/DOI:10.1016/j.ecolind.2005.04.002

Décamps, H. (2001). How a riparian landscape finds form and comes alive. Landscape and Urban Planning, 57, 169-175. doi: http://dx.doi.org/10.1016/S0169-2046(01)00202-X

Elkie, P. C., Rempel, R.S. y Carr, A.P. (1999). Patch Analyst User's Manual. A tool for Quantifying Landscape Structure. Ontario: Ed. Boreal Science, development and produced by Northwest Science \& Technology.

Forman, R.T.T. \& Godron, M. (1981). Patches and structural components for a Landscapes Ecol Bioscience, 31 (10), 733-739. Recuperado de http://www.jstor.org/stable/1308780

Frolova Ignateva, M. (2007). El estudio de los paisajes del agua en una cuenca vertiente: propuesta metodológica. Revista de estudios regionales, 38, 21-47. Recuperado de: http://www.redalyc.org/ pdf/755/75511145001.pdf

Gómez Sal, A. (1997). El paisaje agrario desde la perspectiva de la ecología. En Ciclo de la Agricultura y Ecología: conferencias pronunciadas en el Centre Cultural Bancaixa (pp.145-182). Valencia: Fundación Bancaja.

Gurrutxaga San Vicente, M. \& Lozano Valencia, P. (2006). Efectos de la fragmentación de hábitats y pérdida de conectividad ecológica dentro de la dinámica territorial". Polígonos. Revista de Geografía, 16, 35-34.

Jongman, R.H.G. (2002). Homogenisation and fragmentation of European landscape: ecological consequences and solutions. Landscape and Urban Planning, 58, 211-221. doi: http://dx.doi.org/10.1016/ S0169-2046(01)00222-5

Malanson, G. P. (1993): Riparian Landscapes. Cambridge (etc.): Ed. University Press.

Manuel Valdés, C. (1996). Tierras y montes públicos en la Sierra de Madrid (sectores central y meridional). Madrid: Servicios de publicaciones del Ministerio de Agricultura, Pesca y Alimentación. Recuperado de http://www.magrama.gob.es/ministerio/pags/Biblioteca/fondo/pdf/19135_all.pdf

Mata Olmo, R. \& Fernández Muñoz, S. (2010). Paisajes y patrimonios culturales del agua. La salvaguarda del valor patrimonial de los regadíos tradicionales. Scripta Nova: Revista electrónica de geografía y ciencias sociales, 14, 323-339.

Molina Holgado, P., Sanz Herráiz, C. \& Mata Olmo, R. (2010). Los paisajes del Tajo. Madrid: Ed. Servicios de Publicaciones del Ministerio de Medio Ambiente y Medio Rural y Marino.

Naiman, R. J., Décamps, H., Pastor, J. \& Jonsthon, C.A. (1988). The potential importance of boundaries to fluvial ecosystems. Journal of the North American Benthological Society, 7 (4), 289-306. Recuperado de: http://www.jstor.org/stable/1467295 
Ollero Ojeda, A. (2001). Las riberas del Ebro medio: diagnosis y ordenación de un paisaje fluvial amenazado. En Institución Fernando el Católico (ed.), Una cita europea con la nueva cultura del agua: la directiva marco: perspectivas en Portugal y España: II Congreso Ibérico sobre Planificación y Gestión de Aguas (2.2000) (pp. 139-150).

Padró Simarro, A. (2003). El cultivo del chopo en el marco de la política agraria común y de la unión europea ampliada. El punto de vista de los cultivadores. En Conferencia Internacional sobre el futuro del cultivo de chopo. Roma (13-15 noviembre 2003). Recuperado de: http://www.fao.org/forestry/62610e869ca3leba8a3e09d0d91af8f557611.pdf

Panareda Clopés, J. M. (2009). Evolución en la percepción del paisaje de ribera. Boletín de la Asociación de Geógrafos Españoles, 51, 305-324.

Pautou, G. y Décamps, H. (1985). Ecological interactions between the alluvial forests and hydrology of the Upper Rhône. Archive fur Hydrobiologie, 104, 13-37.

Ribas i Palom, A. (2006). Natura i història en la creació dels "paisatges de l'aigua" a la plana de l'Alt Empordà. Treballs de la Societat Catalana de Geografia, 61-62, 345-364.

Sanz Herráiz, C. (1996). Naturaleza y cultura del agua en el paisaje ibérico. En: Martín Duque, J.F. y Montalvo, J. (coords.) Agua y paisaje: naturaleza, cultura y desarrollo (pp. 101-130). Madrid: Ed. Multimedia Ambiental.

Sterling Carmona, A. (1996) Los sotos, refugio de vida silvestre. Madrid: Ed. Servicio de Publicaciones del Ministerio de Agricultura, Pesca y Alimentación. Secretaría General Técnica, D.L.

Vélez Restrepo, L.A. \& Gómez Sal, A. (2008). Un marco conceptual y analítico para estimar la integridad ecológica a escala de paisaje. Arbor: Ciencia, pensamiento y cultura, 729, 31-44. doi: http://dx.doi.org/ 10.3989/arbor.2008.i729.159

Vila Subirós, J., Varga i Linde, D., Llausàs Pascual, A. \& Ribas i Palom, A.(2006). Conceptos y métodos fundamentales en ecología del paisaje (Landscape ecology). Una interpretación desde la geografía. Documents d'anàlisi geogràfica, 48, 151-166.

Wiens, J.A. (2002). Riverine landscape: taking landscape ecology into the water". En Freshwater Biology, 47, 501-515. doi: http://dx.doi.org/10.1046/j.1365-2427.2002.00887.x

Zoido Naranjo, F. \& Ojeda Rivera, J. (2003) Diversidad, desigualdad y cohesión territorial. En López Ontiveros, A., (coord.) Geografía de Andalucía. Barcelona: Ed. Ariel. 